\title{
1 Smart Film Impacts Stomatal Sensitivity of Greenhouse Capsicum Through Altered
}

\section{Light}

4 Running title: Stomatal sensitivity of Smart Glass-grown Capsicum

6 Chenchen Zhao ${ }^{1,4,5}$, Sachin Chavan ${ }^{1,2}$, Xin $\mathrm{He}^{1,2}$, Meixue Zhou ${ }^{5}$, Christopher I. Cazzonelli ${ }^{1,2}$,

7 Zhong-Hua Chen ${ }^{1,2,4}$, David T. Tissue ${ }^{1,2}$, Oula Ghannoum ${ }^{1,2,3^{*}}$

$9{ }^{1}$ Hawkesbury Institute for the Environment, Western Sydney University, Penrith, NSW 2751,

10 Australia

$11{ }^{2}$ National Vegetable Protected Cropping Centre, Western Sydney University, Hawkesbury

12 Campus, Richmond, NSW 2753, Australia

$13{ }^{3}$ ARC Centre of Excellence for Translational Photosynthesis, Australia

$14{ }^{4}$ School of Science, Western Sydney University, Penrith, NSW 2753, Australia

$15{ }^{5}$ Tasmanian Institute of Agriculture, University of Tasmania, Prospect, TAS, 7250, Australia

$17 *$ Author for Correspondence

18 Oula Ghannoum (O.Ghannoum@westernsydney.edu.au)

19

20 Total words count (excluding Abstract and References): 6299 


\section{Abstract}

23 Optical films that alter light transmittance may reduce energy consumption in high-tech 24 greenhouses, but their impact on crop physiology remains unclear. We compared the stomatal 25 responses of capsicum plants grown hydroponically under control glass (70\% diffuse light) or smart glass (SG) film ULR-80, which blocked $>99 \%$ of ultraviolet light and $19 \%$ of photosynthetically active radiation (PAR). SG had no significant effects on steady-state $\left(g_{s}\right)$ or maximal $\left(g_{\max }\right)$ stomatal conductance. In contrast, SG reduced stomatal pore size and sensitivity to exogenous $\mathrm{ABA}$ thereby increasing rates of leaf water loss, guard cell $\mathrm{K}^{+}$and $\mathrm{Cl}^{-}$efflux, and $\mathrm{Ca}^{2+}$ influx. The transition between low $\left(100 \mu \mathrm{mol} \mathrm{m} \mathrm{m}^{-2} \mathrm{~s}^{-1}\right)$ and high (1500 $\mu \mathrm{mol} \mathrm{m} \mathrm{m}^{-2}$ ) PAR induced faster stomatal closing and opening rates in SG relative to control plants. The fraction of blue light $(0 \%$ or $10 \%)$ did not affect $g_{s}$, but induced stomatal oscillations in SG plants. Increased expression of stomatal closure and photoreceptor genes in epidermal peels of SG plants is consistent with fast stomatal responses to light changes. In conclusion, light intensity was more critical than spectral quality for optimal stomatal responses of capsicum under SG, and re-engineering of the SG should maximize PAR transmission to maintain a better stomatal development.

Keywords: abscisic acid, greenhouse horticulture, light spectrum, smart glass, stomatal conductance, Capsicum annuиm

\section{Highlights}

- Capsicum plants grown under SG film exhibit decreased stomatal pore area, higher water loss and reduced ABA-sensitivity.

- SG-grown plants have faster rates of stomatal closing and opening in response to light intensity changes.

- SG increases efflux of $\mathrm{K}^{+}$and $\mathrm{Cl}^{-}$and influx of $\mathrm{Ca}^{2+}$ of guard cells.

- SG upregulated the expression of key genes involved in stomatal regulation and light sensing. 


\section{Introduction}

Efficient climatic control in protected cropping can be achieved by alterations in greenhouse structures. These include the even-span greenhouse designed for crop cultivation at high latitude (Sethi, 2009), optimal orientation allowing plants to receive more radiation (Xu et al., 2015), different greenhouse shapes to improve the ventilation (Katsoulas et al., 2006), and building materials utilising a special plastic film to block UV radiation and enhance light diffusion (Hemming et al., 2004). Other techniques such as vent, fog, fan cooling systems, dehumidification, and regeneration process of liquid desiccant also improve glasshouse climatic control (Lefers et al., 2016; Rabbi et al., 2019; Samaranayake et al., 2020; White, 2014). However, the high cost of these solutions indicates that an innovative alternative technique of using low emissivity 'smart glass' film, should significantly reduce the costs while maintaining adequate climate control in glasshouses (Lin et al., 2020).

The special glass film materials are optically engineered in a nanometre-scale, adjusting light transmittance to allow for high potential of reducing energy cost in high technology greenhouses (Lin et al., 2020). The "smart glass" (SG) film ULR-80 blocks the majority of UV light and a proportion of far-red and red light, which can reduce energy load required for heating and cooling in a protected cropping situation (Chavan et al., 2020). However, reducing the photosynthetically active radiation (PAR) potentially decreases the growth and productivity of horticultural crops. In a recent study using eggplant grown in a high-tech glasshouse, the application of the SG film led to a net reduction in heat load, water and nutrient consumption and therefore improved energy and resource use efficiency. However, the $19 \%$ decrease in PAR reduced fruit yield of eggplants under SG glass by $25 \%$ compared to normal control glass (Chavan et al., 2020). Whilst SG consistently reduced photosynthetic rates, the response of stomatal conductance was less consistent, decreasing in one season and remaining unaffected in another season (Chavan et al., 2020). Optimal stomatal function is crucial for plant photosynthesis (Farquhar and Sharkey, 1982) and water use efficiency (Lawson and Vialet $\square$ Chabrand, 2019), but can be compromised under adverse light conditions (O'Carrigan et al., 2014). To what extent the effects of altered light conditions generated by a SG film have on stomatal morphology and physiology remains unclear. 
82 PAR, including wavelengths between 400 to $700 \mathrm{~nm}$, supplies the essential photons utilised 83 by plants during photosynthesis, which is highly dependent on its intensity (McCree, 1981).

84 Light directly and indirectly (via photosynthesis) regulates stomatal function (Assmann and 85 Jegla, 2016). Plants have developed sensing mechanisms for both light quantity and quality 86 (Aasamaa and Sõber, 2011; Ballard et al., 2019; Düring and Harst, 2015), to adjust stomatal 87 aperture, allowing $\mathrm{CO}_{2}$ absorption for carbon fixation. Light also plays important roles in 88 stomatal formation, as well as closing and opening of the guard cells (Roelfsema and 89 Hedrich, 2005). As highly specialized cells, guard cells that form the stomatal pore mediate 90 physiological trade-offs to minimize water loss while maximizing carbon gain in the light. An 91 important limitation in this process is the rate at which stomata open in the light or close in 92 darkness, referred to as stomatal conductance (Drake et al., 2013). Rapid stomatal responses 93 to light help to optimise plant photosynthesis (Lawson and Vialet-Chabrand, 2019). 94 Photosynthetic capacity is well linked with the theoretically maximum stomatal conductance $95\left(g_{\max }\right)$ and operational stomatal conductance $\left(g_{o p}\right)$ calculated from stomatal morphological 96 parameters, such as stomatal sizes and stomatal density (McElwain et al., 2016).

98 Long-term effects of light quantity and quality on stomatal density and conductance have 99 been well studied (Savvides et al., 2012). Stomatal density increases under high light (Gay 100 and Hurd, 1975), leading to increased stomatal conductance and $\mathrm{CO}_{2}$ assimilation (Baroli et 101 al., 2008). High light stimulate a rapid stomatal closure along with a rapid production of 102 reactive oxygen species (ROS) (Devireddy et al., 2018). ROS accumulation in guard cells 103 activates key ion channels such as slow anion channel (SLAC1) and outward rectifying $\mathrm{K}^{+}$ 104 channel (GORK) for stomatal closure (Brandt et al., 2012; Deger et al., 2015; Lind et al., 105 2015; Zhao et al., 2018). Moreover, photoreceptors are key players in the response of plant 106 growth and yield to changes of light environment (Babla et al., 2019; Casal, 2013). Blue 107 light-induced stomatal opening is mediated by the light receptor phototropins (PHOT1 and 108 PHOT2) and cryptochromes (CRY1 and CRY2) (Wang et al., 2010), while red light induced 109 stomatal opening is mediated by phytochromes (PHYs) (Wang et al., 2010). Other light110 related genes such as UV-B Photoreceptor 8 (UVR8), Light-Harvesting Component B 111 (LHCB), and Ribulose Bisphosphate Carboxylase Small Chain 1 (RBCS1) can regulate plant 112 photosynthetic rates (Baroli et al., 2008; Borkowska, 2005; Davey et al., 2012; Tossi et al., 
113 2014; Wang et al., 2010; Xu et al., 2012). Their responses to SG may elucidate the potential

114 mechanisms that control the stomatal regulation in capsicum.

115

116 Our overarching hypothesis was that altered light conditions under SG reduce stomatal

117 density and aperture and affect stomatal sensitivity and guard cell ion fluxes due to regulation

118 of ABA and photoreceptors signalling networks. To address this hypothesis, we used

119 Capsicum annuum L., for studying stomatal morphology and physiology. Capsicum, also

120 known as sweet pepper, is the second most cultivated crop after tomatoes in protected

121 cropping in many countries including Australia. Studies on capsicum have mainly focussed

122 on developmental responses to temperature, humidity, and water stress (Bakker, 1989a, b;

123 Hawa, 2003). In this study, we cultivated capsicum plants for 8 months with and without SG

124 film and measured stomatal density, size, guard cell ion fluxes, rate of stomatal response to

125 exogenously applied ABA, and the expression of genes involved in ABA and light signalling

126 networks. We next tested whether signalling pathways triggered by light transitions were

127 altered in a manner that would affect stomatal regulation. We demonstrate that the SG-

128 induced reduction in PAR altered stomatal morphology, behaviour and downstream

129 signalling cascades.

130 


\section{Material and Methods}

\section{$132 \quad$ Plant growth and experimental design}

133 The experiment was conducted from April (Autumn in Australia) to Dec 2019 (Summer in

134 Australia) in the state-of-the-art glasshouse facility at Western Sydney University $\left(33^{\circ} \mathrm{S}\right.$

$135150^{\circ} \mathrm{E}$, Hawkesbury Campus, Richmond, NSW, 2753 Australia). A detailed description of

136 the facility, including software and climate control is presented by Chavan et al. (2020) and

137 Samaranayake et al. (2020). We used four research bays $\left(105 \mathrm{~m}^{2}\right.$ each) with precise

138 environmental control of atmospheric $\mathrm{CO}_{2}$, air temperature, $\mathrm{RH}$, and hydroponic nutrient and

139 water delivery. Capsicum annuum L. seeds (variety Ghia, Syngenta, Australia) were grown in

140 a nursery centre (Withcott Seedlings, Withcott, QLD, 4352 Australia) for six weeks. The

141 seedlings were transplanted in Rockwool slabs and transferred into two control hazed glass

142 (Control) and two SG (Treatment) bays. 
143 The control bays were fitted with HD1AR diffuse glass (70\% haze) and the treatment bays

144 had HD1AR diffuse glass, but were also coated with ULR-80 window film, known as "Smart

145 Glass" (SG) (Solar Gard, Saint-Gobain Performance Plastics, Sydney, Australia). The SG

146 film ULR-80 has a low thermal emissivity (0.87) which blocks the light that mainly

147 contributes to heat, but transmits most of the wavelengths of light used by plants for growth

148 in the PAR region. According to the manufacturer specifications, SG blocks around $88 \%$

149 light in the infrared (IR) and far-infrared (FIR) region between $780 \mathrm{~nm}-2500 \mathrm{~nm}$; and >99\%

150 light in the ultraviolet (UV) region between 300 and $400 \mathrm{~nm}$. SG blocks $43 \%$ of total solar

151 energy with $40 \%$ transmission, $54 \%$ absorption and $6 \%$ reflectance. The two control research

152 bays consist of roof glass (70\% diffuse light) and wall glass (5\% diffuse light). Each bay had

1536 gutters with length at $10.8 \mathrm{~m}$ and width at $25 \mathrm{~cm}$ (AIS Greenworks, Castle Hill, NSW,

154 Australia), which were fitted with 10 Rockwool slabs $(90 \times 15 \times 10 \mathrm{~cm}$, Grodan, The

155 Netherlands) per gutter. Three plants per slab were planted in the four middle gutters, and

156 two plants per slab were planted in the two side gutters which served as buffer plants. Plants

157 were grown in natural light and photoperiod conditions, $25 / 20^{\circ} \mathrm{C}$ (day/night) air temperature,

$15870 / 80 \%$ (day/night) relative humidity, and non-limiting nutrient and water (fertigation)

159 supplied at industry standards. For sample collection and stomatal morphological

160 measurement, unless clarified, top canopy leaves fully exposed to light from each two bays

161 were investigated. Sample collections were completed during sunny conditions on the same

162 day or continuous days to minimise weather effect.

163 Relative water loss measurement

164 Top canopy capsicum leaves which were fully exposed to natural glasshouse light were 165 investigated for relative water loss rate (RWL). RWL was measured using the following 166 equation with modifications (Weatherley, 1950), RWL $=\left(F M-F_{t}\right) / F M \times 100 \%$. Fresh

167 Mass (FM) was determined immediately after samples were collected, and the samples were

168 weighed and recorded as $\mathrm{FM}_{\mathrm{t}}$ on a scale every ten min for 90 mins. Overall, 10-time points

169 (including $0 \mathrm{~min}$ as control) were recorded and the ratio was used to determine differences in

170 the rate of water loss from plants in SG and Control. Five independent leaves from the top

171 canopy of five independent capsicum plants from two bays were collected around 9:00 am on

172 the same day for RWL investigations. 


\section{Stomatal Assay}

174 Stomatal aperture was measured using capsicum epidermal peels from full-expanded top 175 canopy leaves, according to O'Carrigan et al., (2014). Epidermal peels were attached to 35-

$176 \mathrm{~mm}$ glass bottom petri dishes (MatTek Corporation, MA, USA) using silicone adhesive (B177 521, Factor II, InC Lakeside, AZ, USA) and bathed in maintaining solution, referred as 'MS' 178 (50 mM KCl, $5 \mathrm{mM} \mathrm{MES} \mathrm{at} \mathrm{pH} 6.1$ with $\mathrm{KOH}$ ) for about $20 \mathrm{~min}$. Afterward, epidermal peels 179 were imaged in MS under a Nikon microscope attached with a camera and a DS-U3 180 controller (Nikon, Tokyo, Japan). Images of stomatal apertures and sizes were measured and 181 processed with ImageJ software (National Institute of Health, USA). Stomatal density 182 investigations followed a simplified method (Schlüter et al., 2003). Nail polish imprints were 183 taken from the abaxial surface of mature leaves from plants grown under both Control and 184 SG growth rooms. Stomatal densities were determined by light microscopy from leaf 185 imprints of at least five individual plants from both SG and Control growth rooms, 186 respectively. Three independent counts were carried out on each leaf.

187 The method for measuring ABA-induced stomatal aperture changes followed Cai et al., 188 (2017). Manually collected epidermal peels were incubated in MS for $1 \mathrm{~h}$ then rinsed with 189 measuring buffer, referred as 'MB' [10 mM KCl, $5 \mathrm{mM} \mathrm{MES} \mathrm{at} \mathrm{pH} 6.1$ with $\left.\mathrm{Ca}(\mathrm{OH})_{2}\right]$, three

190 times within 10 min. Epidermal peels were imaged in MB for 10 min under light microscopy 191 as a control. Then, $100 \mu \mathrm{M}$ ABA treatment was applied and the peels were imaged for 192 another $50 \mathrm{~min}$. Images were taken every $5 \mathrm{~min}$ and stomatal apertures were measured and 193 analysed with ImageJ. Thirteen-time points (including $0 \mathrm{~min}$ as control) were recorded and 194 the ratio was used to reflect stomatal aperture changes; 30 to 80 stomata from at least three 195 independent epidermal peels were analysed. Epidermal peels were collected at 9 am on sunny 196 days.

\section{Gas exchange measurement}

198 Leaf gas exchange measurements utilised top canopy leaves which were fully exposed to 199 natural glasshouse light, including net assimilation rate $\left(\mathrm{A}_{\mathrm{net}}\right)$ and stomatal conductance $\left(\mathrm{g}_{\mathrm{s}}\right)$, 200 were measured using a Li-Cor Li-6400XT infrared gas analyser according Liu et al., (2017). 201 For investigations of light intensity on photosynthetic parameters, gas exchange 202 measurements were conducted in three stages and took approximately $140 \mathrm{~min}$. The first 203 stage was established under $1500 \mu \mathrm{mol} \mathrm{m} \mathrm{s}^{-2}$ PAR for stabilization (20 min, control stage), 204 followed by the second stage when the light intensity was reduced to $100 \mu \mathrm{mol} \mathrm{m} \mathrm{s}^{-1}$ PAR 
205 and maintained for one hour during the measurement. At the initiation of the third stage, the 206 light intensity was returned to $1500 \square \mathrm{mol} \mathrm{m} \mathrm{m}^{-2} \mathrm{~s}^{-1} \mathrm{PAR}$ and samples were continuously 207 measured for another one hour. At the control stage, after 20 min measurement, stomatal 208 conductance became stable and the average value was used for calculating relative stomatal 209 conductance to the control stage, which reflects the speed of stomatal movements. For 210 investigations of the blue-light spectrum on stomatal conductance changes, three stages were 211 employed. During the first stage, $1500 \mu \mathrm{mol} \mathrm{m}^{-2} \mathrm{~s}^{-1}$ PAR [1350 $\square \mathrm{mol} \mathrm{m}^{-2} \mathrm{~s}^{-1}$ PAR using red 212 LED and $150 \mu \mathrm{mol} \mathrm{m} \mathrm{m}^{-1}$ PAR using blue LED light (10\%)], was employed. After $20 \mathrm{~min}$ 213 measurement, 10\% blue light was switched off and samples were continuously measured for 214 one hour before the third stage, where $10 \%$ blue light ratio was returned, and samples were 215 continuously measured for another one hour. Similarly, average $g_{\mathrm{s}}$ was calculated and used 216 for normalizing the relative $g_{\mathrm{s}}$ changes to the control stage. Gas exchange measurements were 217 conducted between 9 am to 3 pm on sunny days and four individual capsicum plants were 218 measured from both SG and Control.

\section{Stomatal morphological trait measurement and calculation of $g_{\max }$}

220 Operating stomatal conductance $\left(g_{o p}\right)$ was measured according to Drake et al., (2013) and 221 McElwain et al., (2016) with modifications using top canopy capsicum leaves. The $g_{o p}$ 222 measurements were taken in the morning on sunny days with licor-6400XT for measurement 223 with $1500 \mu \mathrm{mol} \mathrm{m} \mathrm{m}^{-1}$ PAR, 70\% ambient humidity, $150 \mu \mathrm{mol} \mathrm{m}^{-2} \mathrm{~s}^{-1}$ air flow and the 224 vapour pressure deficit of $\sim 1 \mathrm{kPa}$. It is noted that capsicum stomatal opening phase took $\sim 100$ 225 min to reach a steady-state $g_{o p} . g_{o p}$ values are means of $g_{o p}$ measurements from four 226 independent capsicum plants using top canopy leaves from both SG and Control at 60-s 227 intervals for the data recording procedures. Maximum theoretical stomatal conductance $\left(g_{\max }\right)$ 228 calculation followed Drake et al., (2013) and McElwain et al., (2016) and utilised stomatal 229 morphological parameters collected based on the stomatal assay:

$230 \quad g_{\max }=\left(\mathrm{dw} / v \cdot \mathrm{SD} \cdot p a_{\max }\right) /\left(p d+\pi / 2 \cdot \operatorname{sqrt}\left(p a_{\max } / \pi\right)\right)$

231 where $\mathrm{dw}=$ diffusivity of water vapour at $25{ }^{\circ} \mathrm{C}\left(0.000025 \mathrm{~m}^{2} \mathrm{~s}^{-1}\right)$ and $v=$ molar volume of 232 air $\left(0.022 \mathrm{~m}^{3} \mathrm{~mol}^{-1}\right)$ are both constantsMcElwain et al., (2016), SD is stomatal density $\left(\mathrm{m}^{-2}\right)$ 233 observed from our stomatal assay, stomatal pore sizes $\left(\mathrm{m}^{2}\right)$ were calculated as an elipse using 234 stomatal pore length $(\mathrm{m})$ as the long axis and $1 / 2$ stomatal pore width $(\mathrm{m})$ as the short axis and $235 p a_{\max }$ (maximum stomatal pore size) was recorded from each replicate among four 
236 independent plants; $p d$ is stomatal pore depth $(\mathrm{m})$ considered to be equivalent to the stomatal

237 width of an fully turgid guard cell (McElwain et al., 2016).

238 Similarly, stomatal sizes $\left(\mu \mathrm{m}^{2}\right)$ were calculated following an elipse using stomatal length $239(\mu \mathrm{m})$ as the long axis and $1 / 2$ stomatal width $(\mu \mathrm{m})$ as the short axis, maximum stomatal sizes

$240\left(S S_{\max }, \mu \mathrm{m}^{2}\right)$ were recorded accordingly from each replicates among four independent 241 capsicum plants. Stomatal opening and closing half-times were calculated from the gas 242 exchange measurement, where stomatal opening half-time was calculated as the time it took 243 to reach the maximum stomatal conductance in response to the light transition from $100 \mu \mathrm{mol}$ $244 \mathrm{~m}^{-2} \mathrm{~s}^{-1}$ to $1500 \mu \mathrm{mol} \mathrm{m} \mathrm{m}^{-2}$ PAR, and stomatal closing half-time was calculated by the time 245 capsicum plants took for reaching the minimum stomatal conductance in response to the light 246 transition from $1500 \mu \mathrm{mol} \mathrm{m} \mathrm{m}^{-2} \mathrm{~s}^{-1}$ to $100 \mu \mathrm{mol} \mathrm{m} \mathrm{m}^{-2} \mathrm{~s}^{-1} \mathrm{PAR}$. Stomatal opening and closing 247 half-times were recorded from four independent capsicum plants of both SG and Control.

\section{Guard cell ion fluxes measurement}

249 For guard cell ion flux measurements, the preparation of epidermal peels was identical to the 250 stomatal bioassay. Net fluxes of $\mathrm{K}^{+}, \mathrm{Cl}^{-}, \mathrm{Ca}^{2+}$, and $\mathrm{H}^{+}$were measured using non-invasive, 251 ion-selective microelectrodes (MIFE) on guard cells of capsicum according to Pornsiriwong 252 et al., (2017) and Zhao et al., (2019). Specific details related to the MIFE theory, electrode 253 fabrication and calibration are described in Shabala et al., (2013). Epidermal peels were pre254 treated with MS for 20 min before blue light treatment. The peels were fixed on a coverslip 255 coated with silicone adhesive and then placed in a long, flat $5 \mathrm{~mL}$ measuring chamber 256 containing MB. Electrodes with fine tips (Resistance $=4$ to $6 \mathrm{G} \Omega$ ) were filled with ion257 selective ionophore cocktails (Sigma, Buchs, Switzerland) and their tips were moved towards 258 and away from the sample in a slow (5 s cycle, $80 \mu \mathrm{m}$ amplitude) square-wave by a 259 computer-driven micromanipulator. Net fluxes of ions from guard cells were calculated from 260 the measured differences in electrochemical potential for these ions between two positions. $261 \mathrm{Net} \mathrm{K}^{+}, \mathrm{Ca}^{2+}, \mathrm{H}^{+}$, and $\mathrm{Cl}^{-}$fluxes from guard cells were measured for $10 \mathrm{~min}$ as a control to 262 ensure initial, steady values before implementing the blue light treatment and then 263 measurements were conducted for another 30 to $40 \mathrm{~min}$. At least five individual stomatal 264 guard cells from independent plants were investigated for ion flux measurements.

\section{Quantitative real time-PCR}

266 Quantitative real-time PCR was performed as previously described (Chen et al., 2016). We 267 measured the transcripts of key genes of abaxial epidermal peels of capsicum leaves. The 
268 details of tested genes can be found in Table S1. Epidermal peels were collected for gene

269 expression investigations to minimize the effect of mesophyll cell mRNA and to enrich the

270 guard cell mRNA (Cai et al., 2017). Fully expanded leaves from the top canopy of four-

271 month-old capsicum plants were selected for sample collection. Under normal light inside

272 growth rooms, the epidermal peel was immediately collected and stored in liquid nitrogen.

273 Total RNA was extracted using a RNeasy Plant Mini Kit (Qiagen, Australia) following the

274 manufacturer's procedure, and the residual genomic DNA was removed with amplification

275 grade DNase I (Ambion). First-strand cDNA was synthesized with the SensiFAST Kit

276 (Bioline, Alexandria, Australia). Fluorescence reflecting target genes expression was

277 determined by the SensiFAST SYBR No-ROX Kit (Bioline, Australia) using gene-specific

278 primers (Table S1) by employing a Rotor-Gene Q6000 (Qiagen). qPCR conditions were

279 composed of three steps of cycling: polymerase activation at $95{ }^{\circ} \mathrm{C}$ for $15 \mathrm{~min}$; 40 cycles

280 were set up for denaturation at $94^{\circ} \mathrm{C}$ for $15 \mathrm{~s}$, annealing for $15 \mathrm{~s}$ at $55^{\circ} \mathrm{C}$, extension at $72{ }^{\circ} \mathrm{C}$

281 for $15 \mathrm{~s}$; SYBR green signal data were acquired at the end. Ubiquitin-conjugating gene (UBI-

282 3) (Wan et al., 2011) was used as the reference for normalization of relative gene expression.

283 Data were expressed as the average of four independent plants from two research bays with

284 two technical replicates.

\section{Statistical analysis}

286 Statistical significance between SG and Control plants, before and after treatment was

287 analysed using Student's t-test and SPSS one-way ANOVA test was applied for statistical

288 analysis of ion flux measurement. All data were presented as means with standard errors. 


\section{Results}

\section{Smart glass (SG) reduced stomatal pore size but not stomatal conductance or density}

292 Light conditions are vital for stomatal formation and development. To investigate stomatal 293 morphological changes induced by SG, we measured stomatal parameters from both control 294 and SG grown plants. Relative to the control glasshouse bays, application of the SG film 295 ULR 80 blocked $99 \%$ of UV, $58 \%$ of far-red, and $26 \%$ of red light, along with a $19 \%$ 296 reduction in PAR. The SG chambers appeared light blue and the control chambers appeared 297 white from the aerial view (Fig. S1A-B). Compared with control plants grown under normal 298 glass condition, plants grown under SG had similar stomatal conductance (Fig. 1B). However, 299 SG significantly decreased stomatal pore size $(P=0.036)$ by $13 \%$ relative to the control (Fig. 300 1C), due to reduced stomatal pore length rather than width (Fig. 1A; Table S2). Stomatal size 301 and density were not statistically different between the control and SG treatments (Fig. 1D-E).

302 These results partially support our hypothesis that altered light conditions under SG will 303 reduce stomatal aperture, indicated by decreased stomatal pore size (length) but not stomatal 304 size or density.

305 SG led to greater leaf water loss, slower ABA-induced stomatal closure and upregulation 306 of ABA signalling genes

307 Did changes in stomatal morphology observed under SG induce physiological or molecular 308 changes in the stomatal response? To answer this question, we compared water loss rate 309 between SG and control plants and subsequently investigated genetic transcripts relating to 310 ABA signalling networks. During the initial $40 \mathrm{~min}$ following leaf detachment, SG and 311 control plants had similar rates of relative water loss. After $60 \mathrm{~min}$, SG leaves transpired 312 water faster than control leaves $(P=0.012$ at $90 \mathrm{~min})$ (Fig. 2A). Given stomata mediate the 313 majority of plant water loss, more water loss from leaves of SG plants indicates a change in 314 stomatal responses. Thus, stomatal closure rate in response to ABA was investigated using 315 epidermal peels, and the initial stomatal aperture before ABA application was not 316 significantly different between the control and SG treatments (Fig. 2B). Exogenously applied 317 ABA caused a slower stomatal closure in SG plants, especially after 40 min of incubation 318 with ABA (Fig. 2B).

319 We then quantified the expression of genes involved in ABA signalling in epidermal peels. 320 PYL8 and CHLH are vital ABA receptors whose mutations both lead to severe open stomata 321 and ABA-insensitive phenotype, whilst overexpression of PYL8 or CHLH leads to high 
322 degrees of stomatal closure (Gonzalez-Guzman et al., 2012; Lim et al., 2013; Shen et al.,

323 2006). Relative to the control, there were significant increases ( 4-6-fold) in PYL8 and

324 CHLH transcripts (Fig. 2C). Since ROS accumulation has been identified as a central

325 network component for stomatal closure (Sierla et al., 2016), core genes encoding ROS

326 metabolism were also investigated [e.g. SOD catalyses the decomposition of hydrogen

327 peroxide $\left(\mathrm{H}_{2} \mathrm{O}_{2}\right)$, the GTP binding protein ADP-ribosylation factor 1 (ARF1) (Dana et al.,

328 2000)]. SG generated a four-fold upregulation of SOD, and $A R F 1$ expression was enhanced

329 by 5-fold in SG compared to the control (Figs 2C and S4). However, the SG treatment

330 showed no significant effect on the expression of Catalase 3 (CAT3), which catalyses the

331 breakdown of $\mathrm{H}_{2} \mathrm{O}_{2}$ into water and oxygen (Fig. S4). Finally, the expression of SLAC1,

332 whose protein contributes to stomatal closure (Deger et al., 2015), was four-fold higher in SG

333 compared to control epidermal peels (Fig. 2C). Taken together, these results support our

334 hypothesis that SG will affect stomatal sensitivity to water stress and ABA-mediated

335 signalling processes.

336 SG stomata responded faster to light transitions without changes in $S S_{\max }, g_{\max }$ or $g_{\text {op }}$

337 To investigate if the SG treatment has altered stomatal sensitivity, we measured changes in 338 stomatal aperture in response to light transitions from 1500 to $100 \mu \mathrm{mol} \mathrm{m}^{-2} \mathrm{~s}^{-1} \mathrm{PAR}$ (Fig.

339 3A). On average, stomata of SG plants showed lower opening and closing half-times relative

340 to the control (Fig. 3B). In particular, SG stomata closed faster in response to the transition to

341 low $\left(100 \mu \mathrm{mol} \mathrm{m} \mathrm{m}^{-2} \mathrm{~s}^{-1}\right) \mathrm{PAR}$, and opened faster in response to the subsequent transition to

342 high PAR (1500 $\mu \mathrm{mol} \mathrm{m} \mathrm{m}^{-2}$ ) (Figs 3A-B). After $140 \mathrm{~min}$ of both light transitions, stomatal

343 conductance was significantly higher in SG relative to control plants (Fig. 3A, Table S2, P <

$3440.01)$.

345 Given the clear link between light conditions and stomatal development (Fu et al., 2010;

346 O'Carrigan et al., 2014), we correlated stomatal parameters with maximum theoretical

347 stomatal conductance $\left(g_{\max }\right)$ and operational stomatal conductance $\left(g_{o p}\right)$. SG and control

348 plants maintained similar $g_{o p}$ and $g_{\max }$ (Table S2). The relationship between $g_{o p}$ and $g_{\max }$ was

349 steeper in SG than control plants (Fig. 3C). Both treatments showed parallel relationships

350 between opening and closing half-times with $g_{\max }$ (Fig. 3D-E) and $g_{o p}$ (Fig, S3C-D). The

351 maximal stomatal size $\left(S S_{\max }\right)$ also showed similar relations with $g_{o p}$ in both treatments (Fig.

352 S3A-B). Overall, SG produced more active stomata in response to light intensity changes

353 with smaller aperture, but not size, supporting our hypothesis that stomatal sensitivity to light

354 conditions will increase due to the altered light condition under SG. 


\section{SG enhanced expression of photoreceptor and photosynthesis genes in epidermal peels}

356 Stomatal conductance was investigated in response to changes in blue light fraction, which is

357

358

359

360

361

362

363

364

365

366

367

368

369

370

371

372

373

374

375

376

377

378

379

380

381

382

383

384

385

386

required for inducing stomatal opening (Inoue and Kinoshita, 2017). SG and control plants responded similarly to blue light (Fig. 4A). During the measurement, there were no differences in stomatal conductance under $1500 \mu \mathrm{mol} \mathrm{m}^{-2} \mathrm{~s}^{-1}$ PAR (Fig. 4B). Removing 10\% blue light (1350 $\left.\mu \mathrm{mol} \mathrm{m} \mathrm{m}^{-2} \mathrm{~s}^{-1} \mathrm{PAR}\right)$ generally induced stomatal closure in both SG and control leaves, while the retrieval of $10 \%$ blue-light increased stomatal conductance similarly in both treatments (Fig. 4B). Accordingly, our hypothesis about increased stomatal sensitivity to blue light under SG is rejected.

Capsicum leaf epidermal peels were used to assess the expression of photoreceptor and photosynthesis associated genes such as PHOT1, PHYA, and RBCS1. Compared with the control, SG grown plants had enhanced gene expression by $75 \%$ in PHOT1, 300\% in PHYA and $165 \%$ in RBCS1 (Figs $4 \mathrm{C}$ and S4). Further, SG plants exhibited increased gene expression of $U V$ light response element $(U V R B)$ and $U V R 8$ relative to control plants (Fig. $4 \mathrm{C})$. These are crucial genes regulating photosynthesis and differential gene expression patterns between SG and control plants, indicating that a different factor was deployed by SG plants to adapt to changed light conditions. Overall, SG stomata maintain a higher sensitivity to light at physiological and molecular levels under glasshouse conditions.

\section{Higher guard cell flux of $\mathrm{K}^{+}, \mathrm{Ca}^{2+}$, and $\mathrm{Cl}^{-}$is induced by SG but suppressed by blue}

\section{light}

Stomatal opening and closing are regulated by ion fluxes across membranes of guard cells. We investigated ion fluxes from guard cells of both treatments. In normal light, guard cells from SG plants showed approximately three times greater efflux of $\mathrm{K}^{+}$and $\mathrm{Cl}^{-}$compared to control plants (Fig. 5A and D), which reduced stomatal aperture and contributed to closure. The $\mathrm{Ca}^{2+}$ influx of guard cells from SG plants was about two times higher than that from control plants (Fig. 5B). The $\mathrm{H}^{+}$efflux of guard cells was similar between SG and control plants under normal light (Fig. 5C).

Blue light significantly suppressed $\mathrm{K}^{+}$efflux of guard cells by $35 \%$ in control and $53 \%$ in SG plants (Fig. 5A). Moreover, blue light also suppressed $\mathrm{Cl}^{-}$efflux by $72 \%$ in $\mathrm{SG}$ and $28 \%$ in control plants (Fig. 5D). Meanwhile, $\mathrm{Ca}^{2+}$ influxes were suppressed by $41 \%$ and $60 \%$ in control and SG, respectively (Fig. 5B). In contrast, blue light slightly induced $\mathrm{H}^{+}$efflux in the control treatment, but slightly suppressed $\mathrm{H}^{+}$efflux in $\mathrm{SG}$, indicating similar effects on SG 
387 and control plants guard cells (Fig. 5C). Overall, SG epidermal peels indicated enhanced

388 solutes loss under normal light condition but maintains ability to response to blue light. This

389 agrees with our hypothesis that long-term altered light conditions under SG will affect guard

390 cell ion fluxes determining stomatal status. 


\section{Discussion}

392 In this study, we compared stomatal functions in upper canopy leaves from capsicum plants 393 grown under SG and control lighting environment. Our results can be categorised into four 394 main findings. Firstly, SG reduced stomatal pore size and increased guard cell fluxes $\left(\mathrm{K}^{+}, \mathrm{Cl}^{-}\right.$ 395 efflux, and $\mathrm{Ca}^{2+}$ influx) and the expression levels of SLAC1 involved mechanism of cellular 396 ion homeostasis without appreciably affecting $\mathrm{g}_{\mathrm{s}}, g_{o p}, g_{\max }$, stomatal size or density. Secondly, 397 SG reduced stomatal sensitivity to ABA, leading to relatively more water loss in detached 398 leaves, and this response was underpinned by upregulation of ABA (PYL8 and CHLH) and 399 ROS (SOD1 and ARF1) related genes. Thirdly, SG stomata responded faster to PAR 400 transitions, such that stomatal opening and closing speed was proportional to $g_{\max }$, whilst the 401 relationship between $g_{o p}$ and $g_{\max }$ was steeper in SG plants. Fourthly, even though SG filtered 402 out light most efficiently in the blue spectrum, dependence of stomatal conductance on blue 403 light was similar between SG and control treatments. Yet, guard cell fluxes showed 404 selectively greater $\left(\mathrm{K}^{+}\right.$and $\left.\mathrm{Ca}^{2+}\right)$ or different $\left(\mathrm{H}^{+}\right)$blue light sensitivities in the SG plants, and 405 this was associated with increased expression of photoreceptor genes (PHOT1 and PHYA) 406 and UV-B light response genes (UVRB, UVR8). Combining all these findings, SG light 407 condition did not impair stomatal ability to respond to light changes of capsicum leaves; 408 instead, the adaptation of SG capsicum stomata to the altered light condition involved a more 409 active response to PAR changes, ABA signalling, and solutes loss to maintain a decreased 410 stomatal pore size under SG light condition.

412 Decreased stomatal pore area in SG is underpinned by enhanced guard cell solute loss 413 and anion channel activity rather than changes in stomatal morphology

414 Stomata regulates plant water-use efficiency by affecting $\mathrm{CO}_{2}$ uptake and photosynthesis as 415 well as transpiration (Brodribb et al., 2009). Under low light conditions, where light 416 reception is limited, full stomatal opening may not be necessary for photosynthesis 417 (Pasternak and Wilson, 1973). A study in sweet pepper suggests that partial shade induced 418 lower stomatal aperture (Jaimez and Rada, 2011). Under SG, where the light intensity was 419 lower than in the control, stomatal pore sizes were significantly smaller in SG than control 420 leaves, due to decreased stomatal pore length (Fig. 1C). We found that there was no 421 difference in stomatal density between SG and control plants (Fig. 1E). Moreover, no 
422 significant difference was observed in most of the stomatal morphological parameters (Table

423 S1), suggesting that ion flux changes may affect the stomatal aperture.

424 Stomatal opening requires activation of potassium inward channels, such as KAT1, KAT2

425 (Ronzier et al., 2014), and AKT1 (Nieves-Cordones et al., 2012), as well as decreased 426 channel activities of potassium outward channel GORK (Hosy et al., 2003). SLAC1 plays a 427 vital role in regulating stomatal response to light (Hiyama et al., 2017), $\mathrm{CO}_{2}$ (Lind et al., 428 2015), and humidity (Vahisalu et al., 2008); stomatal closure in response to drought (Geiger 429 et al., 2009), salinity (Qiu et al., 2016), and darkness (Merilo et al., 2013). Here, SG stomata 430 exhibited significantly higher guard cell efflux of $\mathrm{K}^{+}$and $\mathrm{Cl}^{-}$, which suggests that SG plants 431 close stomata more rapidly than control plants (Fig. 5A and D). Compared with control, SG 432 plants take up about twice more $\mathrm{Ca}^{2+}$ into guard cells (Fig. 5B), which is in agreement with 433 other studies which showed that increased cytosolic $\mathrm{Ca}^{2+}$ activates anion channel (Asano et 434 al., 2012), deactivates potassium inward channels (Ronzier et al., 2014) for stomatal closure 435 (Asano et al., 2012; Zhao et al., 2018). In our study, the higher guard cell efflux of $\mathrm{K}^{+}$and $\mathrm{Cl}^{-}$ 436 and $\mathrm{Ca}^{2+}$ influx under SG reduces cell turgor, thereby decreasing stomatal pore area. SG 437 plants also showed significantly higher expression of SLAC1 responsible for $\mathrm{Cl}^{-}$efflux 438 (Brandt et al., 2012), and higher expression of ABA receptor genes (Fig. 2C). Hence, we 439 propose that SG-induced prolonged low light conditions may increase solute loss, leading to a 440 decrease in stomatal pore area and reduced stomatal conductance.

442 SG deceased stomatal sensitivity to exogenously applied ABA due to up-regulated ABA 443 signalling leading to higher water loss from capsicum leaves

444 Sensing adverse environments and producing ABA for closing stomata has been well 445 established during plant evolution (Lind et al., 2015), and the speed for closing stomata 446 reflects the plant's ability to adapt to a new environment (Pantin et al., 2013; Wang and Chen, 447 2020). A higher relative water loss rate in SG leaves and stomata on plants grown under SG 448 do not open as wide and close more slowly due to the ABA application, indicating that a 449 modified acclimation mechanism for closing stomata developed in plants grown in SG.

450 We investigated transcripts of the critical components of ABA signalling networks. The 451 ABA-induced signalling network consists of critical components, including ABA receptors 452 (Gonzalez-Guzman et al., 2012; Merilo et al., 2013), ROS production (An et al., 2008), Ca ${ }^{2+}$ 453 signalling (Asano et al., 2012; Ronzier et al., 2014) and regulation of ion channels (Deger et 
454 al., 2015; Hosy et al., 2003; Vahisalu et al., 2008). In our study, SG increased expression of 455 ABA receptor gene PYL8 and ABA signalling genes CHLH and ARF1 (Figs 2C and S4), 456 indicating their roles are affected by SG (Liu et al., 2013; Mishra et al., 2006). SOD1 457 functions as a strong ROS remover in plants, which also affects stomatal activity through 458 ROS accumulation (An et al., 2008; Jannat et al., 2011; Jiang and Yang, 2009). Therefore, 459 the upregulated gene expression of SOD1 may suggest ROS accumulation in SG guard cells 460 as part of the SG affected ABA signalling (Figs 2C and S4) to regulate anion channels for 461 stomatal closure (Sierla et al., 2016; Zhao et al., 2018). This was confirmed by increased 462 expression of SLAC1 in SG plants, enhanced guard cell $\mathrm{Cl}^{-}$efflux, and the slow stomatal 463 response to exogenous $\mathrm{ABA}$ treatment. As the $\mathrm{ABA}$ induced stomatal signalling elements 464 were already enhanced, exogenously applied ABA failed to induce further significant 465 stomatal closure in SG plants, leading to a higher water loss rate in SG detached leaves.

467 Faster SG-induced stomatal response to light transitions correlates with $\boldsymbol{g}_{\text {max }}$ without 468 affecting photosynthesis rate

469 Stomatal morphology (e.g. stomatal size), stomatal conductance, and photosynthesis rate are 470 linked to $g_{\max }$ and $g_{\text {op }}$ (Drake et al., 2013), such that faster stomatal reaction speed to light 471 increases $g_{o p}$, thereby improving photosynthesis and water use efficiency (Lawson and 472 Matthews, 2020). We found that SG stomata exhibited faster response rate to light transitions 473 and these rates were linearly correlated with $g_{\max }$. Further analysis showed that SG plants had 474 a narrow range of $g_{\max }$, even though averages of $g_{\max }$ and $g_{o p}$ were not affected by SG. Low 475 PAR generally reduces stomatal conductance and net photosynthetic rate (Farquhar and 476 Sharkey, 1982; Pasternak and Wilson, 1973; Roelfsema and Hedrich, 2005). This is also 477 supported by a previous study, where capsicum plants grown in low light conditions (20\% of 478 control) had reduced stomatal index and $\mathrm{CO}_{2}$-saturated photosynthesis rate (Fu et al., 2010). 479 Here, we found that SG plants exhibited a decreased $g_{\max }$ range and produced slightly smaller 480 stomata, which partly agrees with the above findings. However, SG did not significantly 481 affect net photosynthetic rate (Fig. S2), which may be due to a similar $g_{o p}$ range and relatively 482 high $g_{\max }$.

483 The 'smaller but faster stomata' theory was supported by a multi-species study which found 484 that smaller stomata were usually associated with faster stomatal dynamics (Drake et al., 485 2013; Franks and Beerling, 2009), was summarised in a recent review (Lawson and 
486 Vialet $\square$ Chabrand, 2019). Evolution of faster stomatal response promoted expansion of grasses (Chen et al., 2017), leading to higher plant productivity, efficiency and fitness 488 (Lawson and Vialet $\square$ Chabrand, 2019). In our study, SG plants exhibited smaller stomatal 489 pore size as well as faster opening and closing speed in response to light transitions between $4901500 \mu \mathrm{mol} \mathrm{m} \mathrm{m}^{-2} \mathrm{~s}^{-1}$ PAR to $100 \mu \mathrm{mol} \mathrm{m} \mathrm{m}^{-2} \mathrm{~s}^{-1}$ PAR, which validate the "smaller but faster 491 stomata' theory (Drake et al., 2013) in a greenhouse horticultural crop.

\section{Enhanced expression of light responsive genes underpins the effects of SG on capsicum}

494 Photoreceptors are closely linked with plasma membrane transport, determining plant ionic 495 balance, affecting plant growth, development, and yield (Babla et al., 2019). PHOT1 and 496 PHOT2 were reported to regulate membrane transport via regulating cytosolic $\mathrm{Ca}^{2+}$ in plants 497 (Briggs and Christie, 2002). Further evidence suggests that PHOT1 joins blue light induced $498 \mathrm{Ca}^{2+}$ influx to the cytoplasm and therefore affects significant changes of $\mathrm{Ca}^{2+}$ and $\mathrm{H}^{+}$fluxes 499 (Babourina et al., 2002). In our study, SG plants showed upregulation of PHOT1 along with 500 increased $\mathrm{Ca}^{2+}$ influx. SG reduces $99 \%$ of UV light into the greenhouse bays, which also 501 induced a significantly higher expression of UVR8 (Fig. 4C). In Arabidopsis, UVR8 plays 502 important roles in UV light induced stomatal closure by a mechanism involving both $\mathrm{H}_{2} \mathrm{O}_{2}$ 503 and NO generation in guard cells (Tossi et al., 2014). This further supports our observations

504 of a higher basal level of expression of light responsive genes in SG shows that stomata 505 maintain full capacity to respond to light alternations.

506 To confirm previously reported blue light induced stomatal opening case studies, where 507 crucial ion channels, such as $\mathrm{K}^{+}$(Takahashi et al., 2013), $\mathrm{Ca}^{2+}$ (Ronzier et al., 2014), $\mathrm{H}^{+}$ 508 (Inoue and Kinoshita, 2017) and $\mathrm{Cl}^{-}$(Hiyama et al., 2017), were regulated by blue light, we 509 measured dynamic stomatal conductance during blue light transitions and ion flux changes in 510 response to blue light with no red light background. SG plants exhibited a suppression of $\mathrm{K}^{+}$ 511 and $\mathrm{Cl}^{-}$effluxes and $\mathrm{Ca}^{2+}$ influx (Fig. 5). Absence of blue light slightly decreased stomatal 512 conductance in both SG and control plants, whilst blue light retrieval mildly increased 513 stomatal conductance (Fig. 4B), indicating the key role of blue light in stomatal opening in 514 capsicum (Inoue and Kinoshita, 2017). However, compared with the light retrieval-induced 515 stomatal dynamic changes (Fig. 3A), SG plants stomata obviously responded more actively to 516 light intensity than blue light spectrum (Figs 3A-B and 4A). Overall, SG plants maintain a 517 similar capacity of responding to blue light spectrum but more actively respond to light 
518 intensity relative to the control, and this is highly linked with the increased expression of light

519 responsive genes (Fig. 4C).

\section{Conclusions}

521 Altered light condition in SG did not lead to strong stomatal morphological changes but 522 decreased stomatal aperture, which is the consequence of vigorously activated $\mathrm{ABA}$ and light 523 signalling networks as well as $\mathrm{Ca}^{2+}$ influx and $\mathrm{K}^{+}$and $\mathrm{Cl}^{-}$effluxes from SG guard cells (Fig. 524 6). Interestingly, SG grown plants presented a faster and stronger stomatal recovery when 525 high illumination condition was retrieved, and this was due to the smaller stomatal pore sizes. 526 The faster stomatal response to light may contribute to optimising capsicum photosynthesis 527 under SG light conditions. The current study not only provides valuable physiological 528 implications of SG material on capsicum farming in controlled environment horticulture, but 529 also reveals that SG films could potentially be suitable materials for growing capsicum 530 particularly in the southern hemisphere countries, such as Australia.

531

532 Authors contributions

533 DT, ZHC, CIC and OG designed the Smart Glass experiment that supported this project. The 534 project was conceived by $\mathrm{CZ}, \mathrm{ZHC}$ and $\mathrm{OG}$. CZ and SC performed experimental research 535 and data analyses. CZ, ZHC, OG, DT, and CIC wrote the manuscript with contributions from 536 all co-authors.

\section{Acknowledgments}

539 We thank Dr. Wei Liang for crop growth and management, Ms Chelsea Maier for technical 540 operation and maintenance of the glasshouse, and Dr. Craig Barton for the technical support 541 with Licor 6400XT measurements. We also thank Dr. Juan Zhu from Tasmanian Institute of 542 Agriculture, University of Tasmania for her suggestions on data analysis.

\section{Funding}

545 This work was financially supported by the National Vegetable Protected Cropping Centre 546 and Horticulture Innovation Australia projects VG16070 and VG17003. CZ was supported by 547 the Australian Indian Institute (AII) New Generation Network (NGN) fellowship. OG was 
bioRxiv preprint doi: https://doi.org/10.1101/2020.09.22.309427: this version posted September 24. 2020. The copvriaht holder for this preprint (which was not certified by peer review) is the author/funder, who has granted bioRxiv a license to display the preprint in perpetuity. It is made available under aCC-BY-NC-ND 4.0 International license.

548 partially funded by the Australian Research Council through the Centre of Excellence for

549 Translational Photosynthesis (CE1401000015).

550

\section{Declaration of conflict for interest}

552 No conflict of interest is declared. 


\section{Figure legends}

554 Fig 1. Effect of smart glass (SG) on stomatal traits of capsicum. (A) representative

555 stomatal photos collected from epidermal peels of both control and SG. Scale bar $=20 \mu \mathrm{m}$ (B)

556 stomatal conductance in the Control and SG under control conditions (1500 PAR at initial

557 stable stage). (C-E) stomatal pore size, stomatal size and stomatal density in the control and

$558 \mathrm{SG}\left(\mathrm{n}=5\right.$ biological replicate with 50-80 stomata). Values are means $\pm \mathrm{SE}$. ${ }^{*} \mathrm{P}<0.05$.

Fig 2. Smart glass (SG) alters relative water loss, ABA-induced stomatal closure, and

Fig 3. Effect of smart glass (SG) on stomatal sensitivity to light transitions in capsicum. to 100 PAR for 1 hour and followed by 1500 PAR for another $1 \mathrm{~h}$. The averaged stomatal conductance value from the initial 20 min was used for normalizing stomatal conductance ratios to the initial control stage. (B) half stomatal opening time (t1/2o) and half stomatal closure time $(\mathrm{t} 1 / 2 \mathrm{c})$ in response to light transitions. (C-E) correlation analysis between maximum theoretical stomatal conductance $\left(g_{\max }\right)$ and operational stomatal conductance $\left(g_{o p}\right)$ and stomatal opening and closing half-times $\left(t_{1 / 2}\right)$. Data are means $\pm \mathrm{SE}(\mathrm{n}=4) .{ }^{*} \mathrm{P}<0.05$; $* * \mathrm{P}<0.01$.

Fig 4. Smart glass (SG) induces different stomatal responses to blue light and gene 580 expression in capsicum. (A) stomatal conductance was monitored in three light conditions: normal light (1500 PAR: 1350 Red + 150 Blue) for $20 \mathrm{~min}, 1350$ Red PAR for 1 hour, and normal light for another $1 \mathrm{~h}$. The averaged stomatal conductance value from the initial 20 min measurement was used for normalizing stomatal conductance ratios. (B), bar graphs are three points of the end of each light condition. Data are means \pm SE $(n=4)$ (C) gene expression of Phototropin 1 (PHOT1), Phytochrome A (PHYA), UV response elements $(U V R B)$ and $U V-B$ Receptor $8(U V R 8)$. Data are means $\pm \mathrm{SE}(\mathrm{n}=4$ biological replicates with 2 technical replicates). $* \mathrm{P}<0.05 ; * * \mathrm{P}<0.01$.

Fig 5 Smart glass (SG) affects ion fluxes and their regulation by blue light in guard cell cells in leaf epidermal peels. Data are means \pm SE ( $n=5$ to 7 plants). Different lowercase

Fig 6 Schematic summary of smart glass (SG)-induced low light condition on guard cell signalling network in capsicum. Under prolonged low light conditions, ABA reception was highly upregulated, leading to the ROS accumulation in guard cells. ROS activated $\mathrm{Ca}^{2+}$ influx and thus induced cytosolic $\mathrm{Ca}^{2+}$ accumulation in guard cells. Accumulated ROS and 
$598 \mathrm{Ca}^{2+}$ suppressed $\mathrm{K}^{+}$inward channels AKT1/KAT1 and activated slow anion channels 599 SLAC1(Brandt et al., 2012) and $\mathrm{K}^{+}$outward channel GORK. Besides, photosynthesis related 600 genes also play roles in inducing stomatal closure by accumulating starch in guard cells.

601

602

\section{Supplementary Information}

604 Fig S1. Mechanism of smart glass material and an external view of the greenhouse fitted with 605 SG.

Fig S2. Effect of smart glass (SG) on net photosynthetic rate of capsicum under light 609

610 Fig S3. Correlation analysis of the effect of smart glass (SG) on the maximum theoretical 611 stomatal conductance $\left(g_{\max }\right)$, maximum stomatal sizes $\left(S S_{\max }\right)$, stomatal opening and closing 612 half-times $\left(t_{1 / 2}\right)$ with operational stomatal conductance $\left(g_{\text {op }}\right)$ of capsicum.

613

614 Fig S4 Relative expression of genes relevant to ABA signalling, ROS metabolism and 615 photosynthesis in capsicum epidermal peels under control and smart glass (SG).

616

617 Table S1 Primers and gene information in the quantitative RT-PCR experiment.

618

619 Table S2. Comparison of stomatal traits, gas exchange parameters, and ion fluxes of 620 capsicum between control and smart glass (SG) conditions. 


\section{References}

Aasamaa K, Sõber A. 2011. Stomatal sensitivities to changes in leaf water potential, air humidity, $\mathrm{CO}_{2}$ concentration and light intensity, and the effect of abscisic acid on the sensitivities in six temperate deciduous tree species. Environmental and Experimental Botany 71, 72-78.

An Z, Jing W, Liu Y, Zhang W. 2008. Hydrogen peroxide generated by copper amine oxidase is involved in abscisic acid-induced stomatal closure in Vicia faba. Journal of Experimental Botany 59, 815-825.

Asano T, Hayashi N, Kikuchi S, Ohsugi R. 2012. CDPK-mediated abiotic stress signaling. Plant Signaling \& Behavior 7, 817-821.

Assmann S, Jegla T. 2016. Guard cell sensory systems: recent insights on stomatal responses to light, abscisic acid, and $\mathrm{CO}_{2}$. Current Opinion in Plant Biology 33, 157-167

Babla M, Cai S, Chen G, Tissue DT, Cazzonelli CI, Chen ZH. 2019. Molecular evolution and interaction of membrane transport and photoreception in plants. Frontiers in Genetics 10, 956.

Babourina O, Newman I, Shabala S. 2002. Blue light-induced kinetics of $\mathrm{H}^{+}$and $\mathrm{Ca}^{2+}$ fluxes in etiolated wild-type and phototropin-mutant Arabidopsis seedlings. Proceedings of the National Academy of Sciences 99, 2433-2438.

Bakker J. 1989a. The effects of air humidity on flowering, fruit set, seed set and fruit growth of glasshouse sweet pepper (Capsicum annuиm L.). Scientia Horticulturae 40, 1-8.

Bakker J. 1989b. The effects of temperature on flowering, fruit set and fruit development of glasshouse sweet pepper (Capsicum annuиm L.). Journal of Horticultural Science 64, 313320.

Ballard T, Peak D, Mott K. 2019. Blue and red light effects on stomatal oscillations. Functional Plant Biology 46, 146-151.

Baroli I, Price GD, Badger MR, von Caemmerer S. 2008. The contribution of photosynthesis to the red light response of stomatal conductance. Plant Physiology 146, 737747.

Borkowska B. 2005. The photosynthetic activity of plants growing under different environmental conditions. International Journal of Fruit Science 5, 3-16.

Brandt B, Brodsky DE, Xue S, Negi J, Iba K, Kangasjärvi J, Ghassemian M, Stephan AB, Hu H, Schroeder JI. 2012. Reconstitution of abscisic acid activation of SLAC1 anion channel by CPK6 and OST1 kinases and branched ABI1 PP2C phosphatase action. Proceedings of the National Academy of Sciences 109, 10593-10598.

Briggs WR, Christie JM. 2002. Phototropins 1 and 2: versatile plant blue-light receptors. Trends in Plant Science 7, 204-210.

Brodribb TJ, McAdam SA, Jordan GJ, Feild TS. 2009. Evolution of stomatal responsiveness to $\mathrm{CO}_{2}$ and optimization of water - use efficiency among land plants. New Phytologist 183, 839-847.

Cai S, Chen G, Wang Y, Huang Y, Marchant DB, Wang Y, Yang Q, Dai F, Hills A, Franks PJ. 2017. Evolutionary conservation of ABA signaling for stomatal closure. Plant Physiology 174, 732-747. 
Casal JJ. 2013. Photoreceptor signaling networks in plant responses to shade. Annual Review of Plant Biology 64, 403-427.

Chavan SG, Maier C, Alagoz Y, Filipe JC, Warren CR, Lin H, Jia B, Loik ME, Cazzonelli CI, Chen Z. 2020. Light limited photosynthesis under energy-saving film decreases eggplant yield. ESSOAr doi: 10.1002/essoar.10502325.1

Chen ZH, Chen G, Dai F, Wang Y, Hills A, Ruan Y-L, Zhang G, Franks PJ, Nevo E, Blatt MR. 2017. Molecular evolution of grass stomata. Trends in Plant Science 22, 124-139.

Chen ZH, Wang Y, Wang JW, Babla M, Zhao C, García - Mata C, Sani E, Differ C, Mak M, Hills A. 2016. Nitrate reductase mutation alters potassium nutrition as well as nitric oxide - mediated control of guard cell ion channels in Arabidopsis. New Phytologist 209, 1456-1469.

Dana RR, Eigsti C, Holmes KL, Leto TL. 2000. A regulatory role for ADP-ribosylation factor 6 (ARF6) in activation of the phagocyte NADPH oxidase. Journal of Biological Chemistry 275, 32566-32571.

Davey MP, Susanti NI, Wargent JJ, Findlay JE, Quick WP, Paul ND, Jenkins GI. 2012. The UV-B photoreceptor UVR8 promotes photosynthetic efficiency in Arabidopsis thaliana exposed to elevated levels of UV-B. Photosynthesis Research 114, 121-131.

Deger AG, Scherzer S, Nuhkat M, Kedzierska J, Kollist H, Brosché M, Unyayar S, Boudsocq M, Hedrich R, Roelfsema MRG. 2015. Guard cell SLAC1-type anion channels mediate flagellin - induced stomatal closure. New Phytologist 208, 162-173.

Devireddy AR, Zandalinas SI, Gómez-Cadenas A, Blumwald E, Mittler R. 2018. Coordinating the overall stomatal response of plants: Rapid leaf-to-leaf communication during light stress. Sci Signal. 11, eaam9514.

Drake PL, Froend RH, Franks PJ. 2013. Smaller, faster stomata: scaling of stomatal size, rate of response, and stomatal conductance. Journal of Experimental Botany 64, 495-505.

Düring H, Harst M. 2015. Stomatal behaviour, photosynthesis and photorespiration of in vitro-grown grapevines: effects of light and $\mathrm{CO}_{2}$. VITIS-Journal of Grapevine Research 35, 163.

Farquhar GD, Sharkey TD. 1982. Stomatal conductance and photosynthesis. Annual Review of Plant Physiology 33, 317-345.

Franks PJ, Beerling DJ. 2009. Maximum leaf conductance driven by $\mathrm{CO}_{2}$ effects on stomatal size and density over geologic time. Proceedings of the National Academy of Sciences 106, 10343-10347.

Fu Q, Zhao B, Wang Y, Ren S, Guo Y. 2010. Stomatal development and associated photosynthetic performance of capsicum in response to differential light availabilities. Photosynthetica 48, 189-198.

Gay A, Hurd R. 1975. The influence of light on stomatal density in the tomato. New Phytologist 75, 37-46.

Geiger D, Scherzer S, Mumm P, Stange A, Marten I, Bauer H, Ache P, Matschi S, Liese A, Al-Rasheid KA. 2009. Activity of guard cell anion channel SLAC1 is controlled by drought-stress signaling kinase-phosphatase pair. Proceedings of the National Academy of Sciences 106, 21425-21430. 
Gonzalez-Guzman M, Pizzio GA, Antoni R, Vera-Sirera F, Merilo E, Bassel GW, Fernández MA, Holdsworth MJ, Perez-Amador MA, Kollist H. 2012. Arabidopsis PYR/PYL/RCAR receptors play a major role in quantitative regulation of stomatal aperture and transcriptional response to abscisic acid. The Plant Cell 24, 2483-2496.

Hawa Z. 2003. Effects of water stress on anthesis and flower abscission in the glasshouse sweet pepper (Capsicum annuum L.). Malaysian Society of Plant Physiology 12, 108-116

Hemming S, Waaijenberg D, Campen JB, Bot GP. 2004. Development of a greenhouse system for tropical lowland in Indonesia. Acta Horticulturae 710, 135-142.

Hiyama A, Takemiya A, Munemasa S, Okuma E, Sugiyama N, Tada Y, Murata Y, Shimazaki KI. 2017. Blue light and $\mathrm{CO}_{2}$ signals converge to regulate light-induced stomatal opening. Nature communications 8, 1-13.

Hosy E, Vavasseur A, Mouline K, Dreyer I, Gaymard F, Porée F, Boucherez J, Lebaudy A, Bouchez D, Véry AA. 2003. The Arabidopsis outward $\mathrm{K}^{+}$channel GORK is involved in regulation of stomatal movements and plant transpiration. Proceedings of the National Academy of Sciences 100, 5549-5554.

Inoue SI, Kinoshita T. 2017. Blue light regulation of stomatal opening and the plasma membrane $\mathrm{H}^{+}$-ATPase. Plant Physiology 174, 531-538.

Jaimez RE, Rada F. 2011. Gas exchange in sweet pepper (Capsicum chinense Jacq) under different light conditions. Journal of Agricultural Science 3, 134.

Jannat R, Uraji M, Morofuji M, Islam MM, Bloom RE, Nakamura Y, McClung CR, Schroeder JI, Mori IC, Murata Y. 2011. Roles of intracellular hydrogen peroxide accumulation in abscisic acid signaling in Arabidopsis guard cells. Journal of Plant Physiology 168, 1919-1926.

Jiang L, Yang H. 2009. Prometryne-induced oxidative stress and impact on antioxidant enzymes in wheat. Ecotoxicology and Environmental Safety 72, 1687-1693.

Katsoulas N, Bartzanas T, Boulard T, Mermier M, Kittas C. 2006. Effect of vent openings and insect screens on greenhouse ventilation. Biosystems Engineering 93, 427-436.

Lawson T, Matthews J. 2020. Guard cell metabolism and stomatal function. Annual Review of Plant Biology 71, 30.

Lawson T, Vialet-Chabrand S. 2019. Speedy stomata, photosynthesis and plant water use efficiency. New Phytologist 221, 93-98.

Lefers R, Bettahalli NMS, Nunes SP, Fedoroff N, Davies PA, Leiknes T. 2016. Liquid desiccant dehumidification and regeneration process to meet cooling and freshwater needs of desert greenhouses. Desalination and Water Treatment 57, 23430-23442.

Lim CW, Baek W, Han SW, Lee SC. 2013. Arabidopsis PYL8 plays an important role for ABA signaling and drought stress responses. The Plant Pathology Journal 29, 471-476.

Lin KT, Lin H, Jia B. 2020. Plasmonic nanostructures in photodetection, energy conversion and beyond. Nanophotonics 9, 3135-3163.

Lind C, Dreyer I, López-Sanjurjo EJ, von Meyer K, Ishizaki K, Kohchi T, Lang D, Zhao Y, Kreuzer I, Al-Rasheid KA. 2015. Stomatal guard cells co-opted an ancient ABAdependent desiccation survival system to regulate stomatal closure. Current Biology 25, 928935. 
Liu X, Fan Y, Mak M, Babla M, Holford P, Wang F, Chen G, Scott G, Wang G, Shabala S. 2017. QTLs for stomatal and photosynthetic traits related to salinity tolerance in barley. BMC Genomics 18, 9.

Liu X, Zhang H, Zhao Y, Feng Z, Li Q, Yang H-Q, Luan S, Li J, He ZH. 2013. Auxin controls seed dormancy through stimulation of abscisic acid signaling by inducing ARFmediated ABI3 activation in Arabidopsis. Proceedings of the National Academy of Sciences 110, 15485-15490.

McCree KJ. 1981. Photosynthetically active radiation. Physiological plant ecology I: Springer, 41-55.

McElwain JC, Yiotis C, Lawson T. 2016. Using modern plant trait relationships between observed and theoretical maximum stomatal conductance and vein density to examine patterns of plant macroevolution. New Phytologist 209, 94-103.

Merilo E, Laanemets K, Hu H, Xue S, Jakobson L, Tulva I, Gonzalez-Guzman M, Rodriguez PL, Schroeder JI, Broschè M. 2013. PYR/RCAR receptors contribute to ozone-, reduced air humidity-, darkness-, and $\mathrm{CO}_{2}$-induced stomatal regulation. Plant Physiology 162, 1652-1668.

Mishra G, Zhang W, Deng F, Zhao J, Wang X. 2006. A bifurcating pathway directs abscisic acid effects on stomatal closure and opening in Arabidopsis. Science 312, 264-266.

Nieves-Cordones M, Caballero F, Martínez V, Rubio F. 2012. Disruption of the Arabidopsis thaliana inward-rectifier $\mathrm{K}^{+}$channel AKT1 improves plant responses to water stress. Plant and Cell Physiology 53, 423-432.

O'Carrigan A, Hinde E, Lu N, Xu XQ, Duan H, Huang G, Mak M, Bellotti B, Chen ZH. 2014. Effects of light irradiance on stomatal regulation and growth of tomato. Environmental and Experimental Botany 98, 65-73.

Pantin F, Renaud J, Barbier F, Vavasseur A, Le Thiec D, Rose C, Bariac T, Casson S, McLachlan DH, Hetherington AM. 2013. Developmental priming of stomatal sensitivity to abscisic acid by leaf microclimate. Current Biology 23, 1805-1811.

Pasternak D, Wilson G. 1973. Illuminance, stomatal opening, and photosynthesis in sorghum and cotton. Australian Journal of Agricultural Research 24, 527-532.

Pornsiriwong W, Estavillo GM, Chan KX, Tee EE, Ganguly D, Crisp PA, Phua SY, Zhao C, Qiu J, Park J. 2017. A chloroplast retrograde signal, 3'-phosphoadenosine 5'phosphate, acts as a secondary messenger in abscisic acid signaling in stomatal closure and germination. Elife 6, e23361.

Qiu J, Henderson SW, Tester M, Roy SJ, Gilliham M. 2016. SLAH1, a homologue of the slow type anion channel SLAC1, modulates shoot $\mathrm{Cl}^{-}$accumulation and salt tolerance in Arabidopsis thaliana. Journal of Experimental Botany 67, 4495-4505.

Rabbi B, Chen ZH, Sethuvenkatraman S. 2019. Protected cropping in warm climates: a review of humidity control and cooling methods. Energies 12, 2737.

Roelfsema MRG, Hedrich R. 2005. In the light of stomatal opening: new insights into "the Watergate'. New Phytologist 167, 665-691.

Ronzier E, Corratgé-Faillie C, Sanchez F, Prado K, Brière C, Leonhardt N, Thibaud JB, Xiong TC. 2014. CPK13, a noncanonical $\mathrm{Ca}^{2+}$-dependent protein kinase, specifically inhibits KAT2 and KAT1 shaker $\mathrm{K}^{+}$channels and reduces stomatal opening. Plant Physiology 166, 314-326. 
Samaranayake P, Liang W, Chen ZH, Tissue D, Lan YC. 2020. Sustainable Protected Cropping: A Case Study of Seasonal Impacts on Greenhouse Energy Consumption during Capsicum Production. Energies 13, 4468.

Savvides A, Fanourakis D, van Ieperen W. 2012. Co-ordination of hydraulic and stomatal conductances across light qualities in cucumber leaves. Journal of Experimental Botany 63, 1135-1143.

Schlüter U, Muschak M, Berger D, Altmann T. 2003. Photosynthetic performance of an Arabidopsis mutant with elevated stomatal density (sdd1-1) under different light regimes. Journal of Experimental Botany 54, 867-874.

Sethi VP. 2009. On the selection of shape and orientation of a greenhouse: Thermal modeling and experimental validation. Solar Energy 83, 21-38.

Shabala S, Shabala L, Bose J, Cuin T, Newman I. 2013. Ion flux measurements using the MIFE technique. Plant Mineral Nutrients: Springer, 171-183.

Shen YY, Wang XF, Wu FQ, Du SY, Cao Z, Shang Y, Wang XL, Peng CC, Yu XC, Zhu SY. 2006. The Mg-chelatase H subunit is an abscisic acid receptor. Nature 443, 823-826.

Sierla M, Waszczak C, Vahisalu T, Kangasjärvi J. 2016. Reactive oxygen species in the regulation of stomatal movements. Plant Physiology 171, 1569-1580.

Takahashi Y, Ebisu Y, Kinoshita T, Doi M, Okuma E, Murata Y, Shimazaki KI. 2013. bHLH transcription factors that facilitate $\mathrm{K}^{+}$uptake during stomatal opening are repressed by abscisic acid through phosphorylation. Sci Signal. 6, ra48-ra48.

Tossi VE, Lamattina L, Jenkins G, Cassia R. 2014. Ultraviolet-B-induced stomatal closure in Arabidopsis is regulated by the UVR8 photoreceptor in a nitric oxide-dependent mechanism. Plant Physiology 164, 2220-2230

Vahisalu T, Kollist H, Wang YF, Nishimura N, Chan WY, Valerio G, Lamminmäki A, Brosché M, Moldau H, Desikan R. 2008. SLAC1 is required for plant guard cell S-type anion channel function in stomatal signalling. Nature 452, 487-491.

Wan H, Yuan W, Ruan M, Ye Q, Wang R, Li Z, Zhou G, Yao Z, Zhao J, Liu S. 2011. Identification of reference genes for reverse transcription quantitative real-time PCR normalization in pepper (Capsicum annuum L.). Biochemical and Biophysical Research Communications 416, 24-30.

Wang FF, Lian HL, Kang CY, Yang HQ. 2010. Phytochrome B is involved in mediating red light-induced stomatal opening in Arabidopsis thaliana. Molecular Plant 3, 246-259.

Wang Y, Chen ZH. 2020. Does Molecular and Structural Evolution Shape the Speedy Grass Stomata? Frontiers in Plant Science 11, 333.

Weatherley P. 1950. Studies in the water relations of the cotton plant: I. The field measurement of water deficits in leaves. New Phytologist 49, 81-97.

White RJ. 2014. Vent, fog and fan, a cooling system for large greenhouses in hot weather with low humidity. XXIX International Horticultural Congress on Horticulture: Sustaining Lives, Livelihoods and Landscapes (IHC2014): 1107, 61-66.

Xu J, Li Y, Wang R, Liu W, Zhou P. 2015. Experimental performance of evaporative cooling pad systems in greenhouses in humid subtropical climates. Applied Energy 138, 291301. 
Xu YH, Liu R, Yan L, Liu ZQ, Jiang SC, Shen YY, Wang XF, Zhang DP. 2012. Lightharvesting chlorophyll $\mathrm{a} / \mathrm{b}$-binding proteins are required for stomatal response to abscisic acid in Arabidopsis. Journal of Experimental Botany 63, 1095-1106.

Zhao C, Haigh AM, Holford P, Chen ZH. 2018. Roles of chloroplast retrograde signals and ion transport in plant drought tolerance. International Journal of Molecular Sciences 19, 963.

Zhao C, Wang Y, Chan KX, Marchant DB, Franks PJ, Randall D, Tee EE, Chen G, Ramesh S, Phua SY. 2019. Evolution of chloroplast retrograde signaling facilitates green plant adaptation to land. Proceedings of the National Academy of Sciences 116, 5015-5020. 

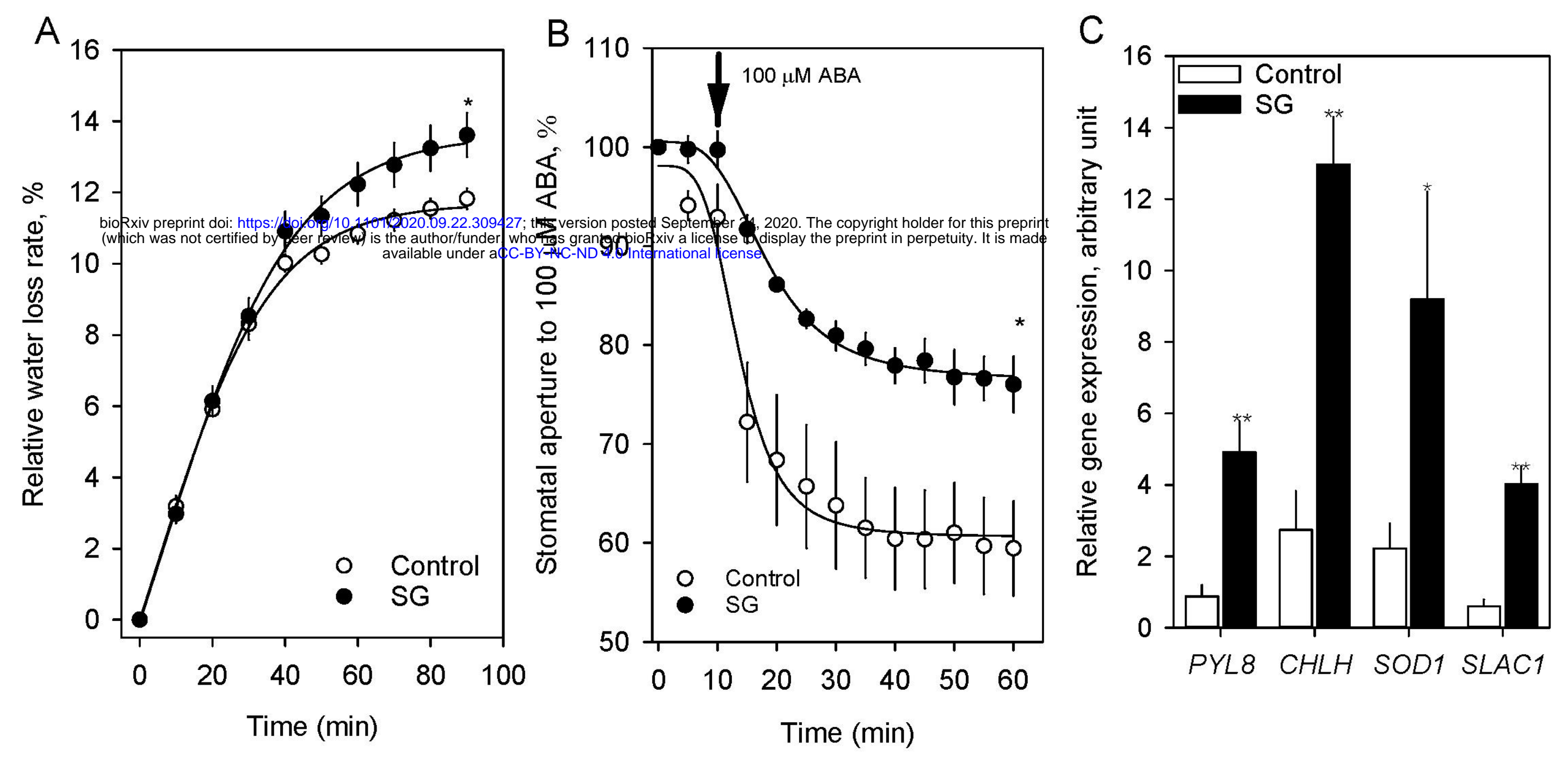

Fig 2. Smart glass (SG) alters relative water loss, ABA-induced stomatal closure, and expression of genes of ABA signalling in capsicum. (A) relative water loss was calculated based on the mass loss every ten min. Values are means $\pm \mathrm{SE}(\mathrm{n}=5)$. (B) stomatal response to exogenous $100 \mu \mathrm{M}$ ABA. Data are mean $\pm \mathrm{SE}(\mathrm{n}=4$ biological replicates from 30 to 80 stomata). (C) relative expression of genes of ABA signalling from epidermis. Pyrabactin resistance8 (PYL8), Mg-chelatase H subunit (CHLH); superoxide dismutase $(S O D)$ and slow anion channel-associated 1 (SLACl). Data are means $\pm \mathrm{SD}(\mathrm{n}=4$ biological replicates with 2 technical replicates). ${ }^{*} \mathrm{P}<0.05 ; * * \mathrm{P}<0.01$. 

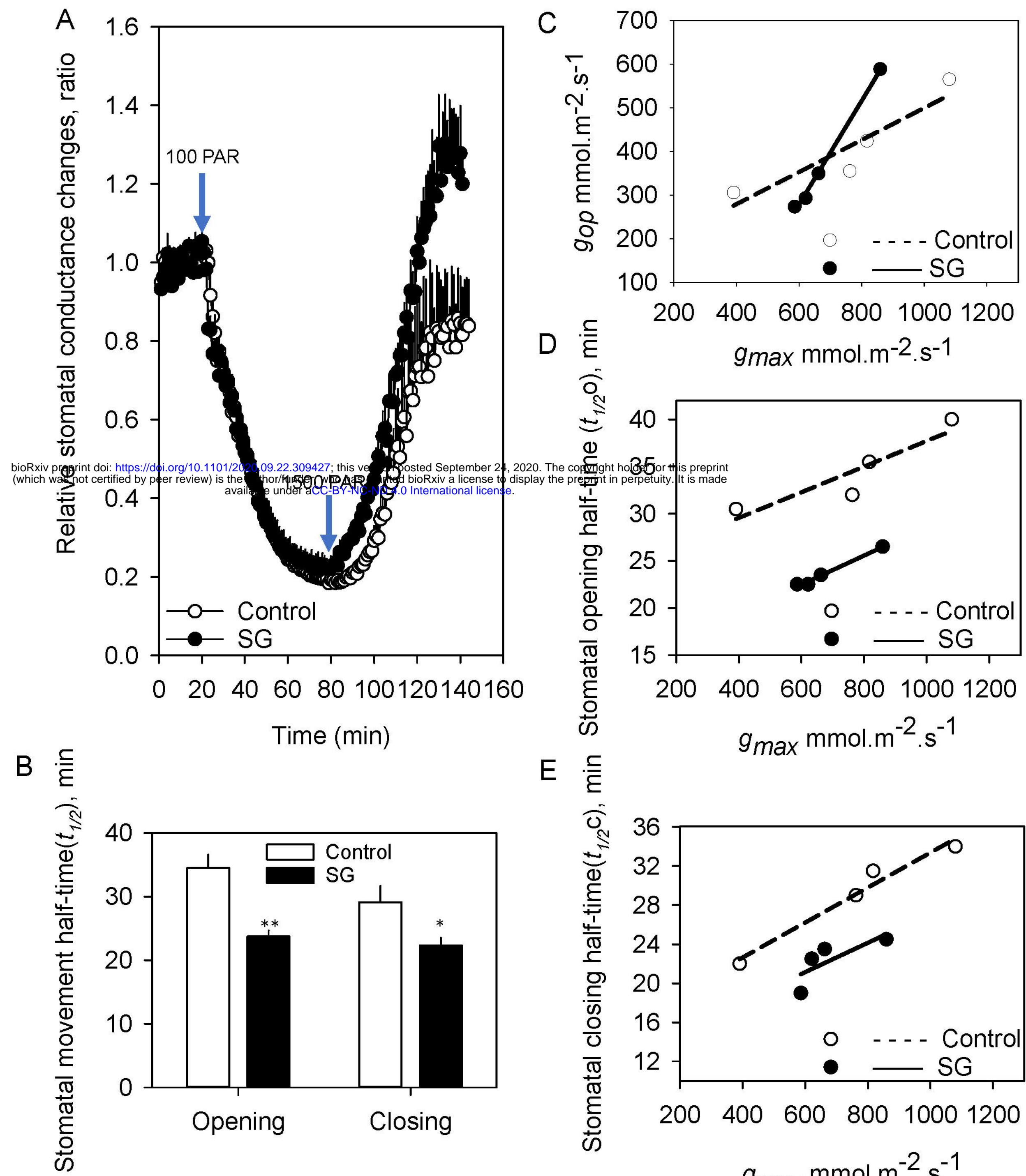

. 
A

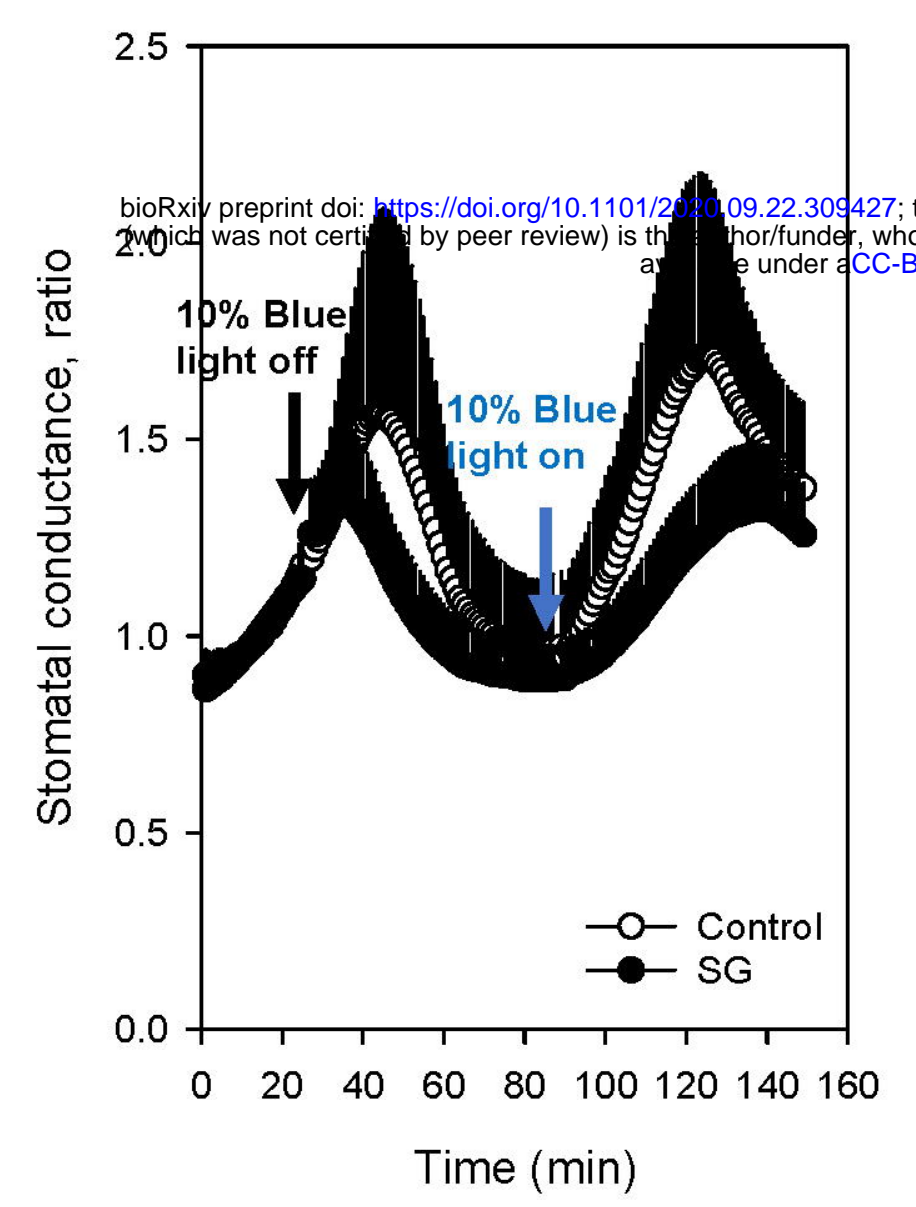

B

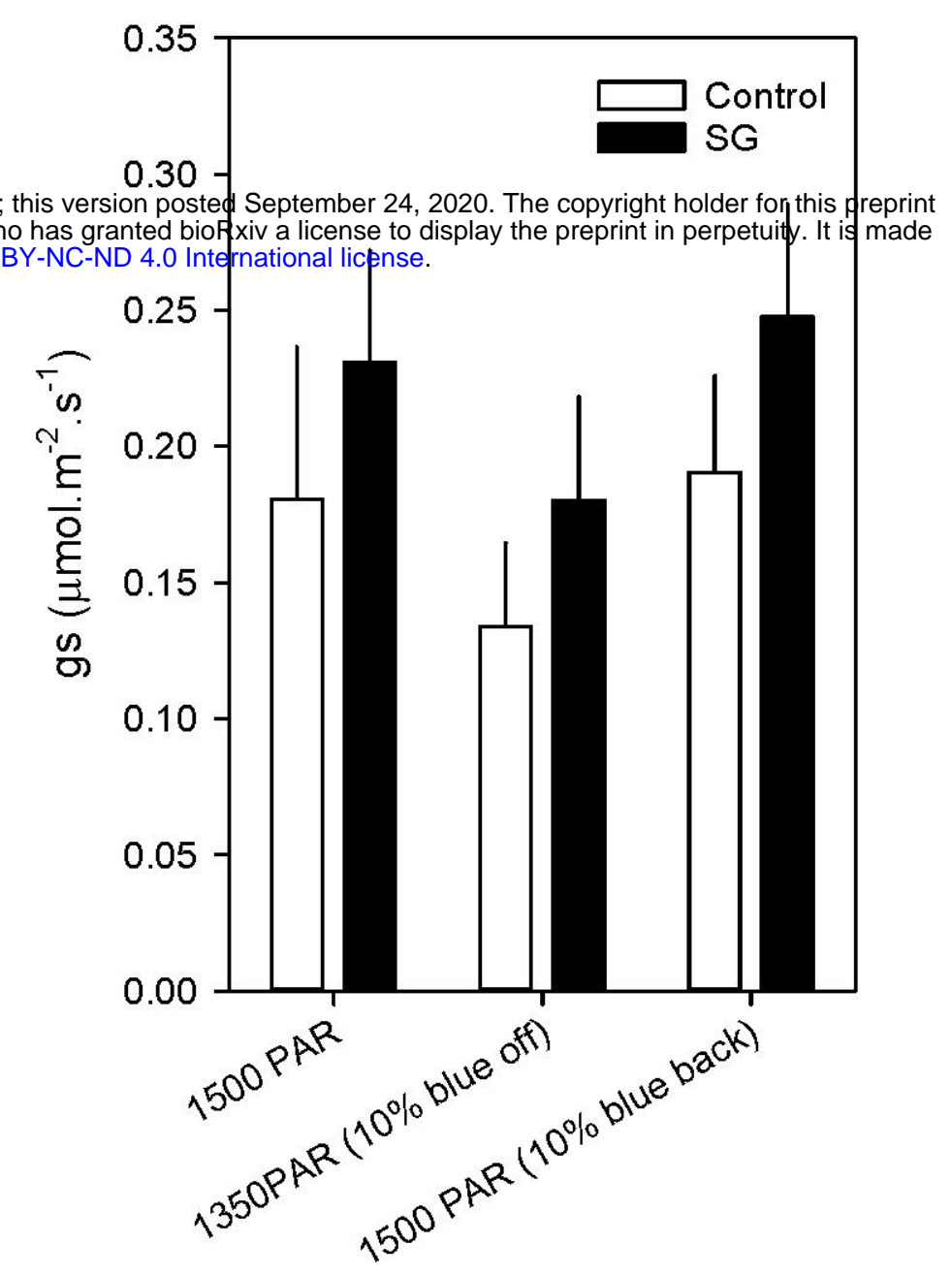

C

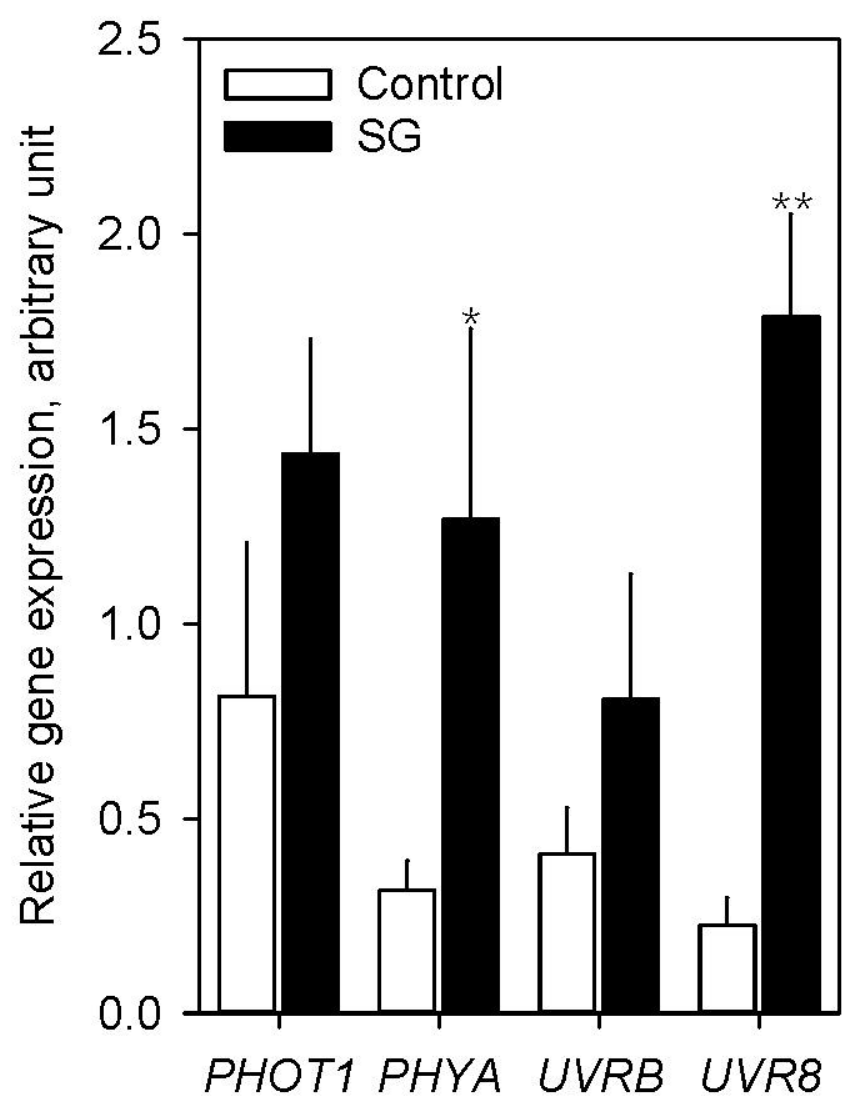

Fig 4. Smart glass (SG) induces different stomatal responses to blue light and gene expression in capsicum. (A) stomatal conductance was monitored in three light conditions: normal light (1500 PAR: 1350 Red +150 Blue) for 20 min, 1350 Red PAR for 1 hour, and normal light for another $1 \mathrm{~h}$. The averaged stomatal conductance value from the initial $20 \mathrm{~min}$ measurement was used for normalizing stomatal conductance ratios. (B), bar graphs are three points of the end of each light condition. Data are means $\pm \mathrm{SE}(\mathrm{n}=4)(\mathrm{C})$ gene expression of Phototropin 1 (PHOT1), Phytochrome A (PHYA), UV response elements (UVRB) and UV-B Receptor 8 (UVR8). Data are means $\pm \mathrm{SE}(\mathrm{n}=4$ biological replicates with 2 technical replicates). ${ }^{*} \mathrm{P}<0.05 ;{ }^{*} \mathrm{P}<0.01$. 
A

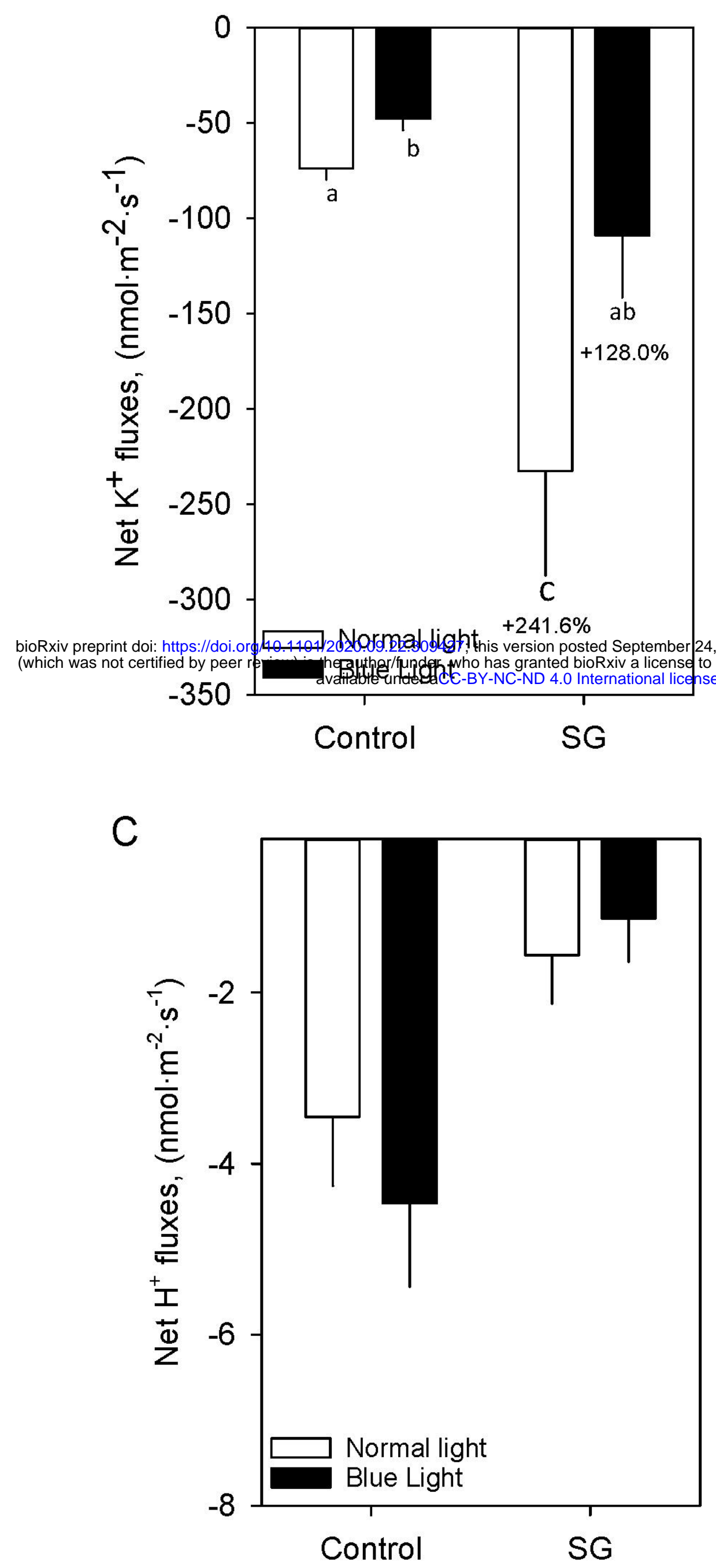

B

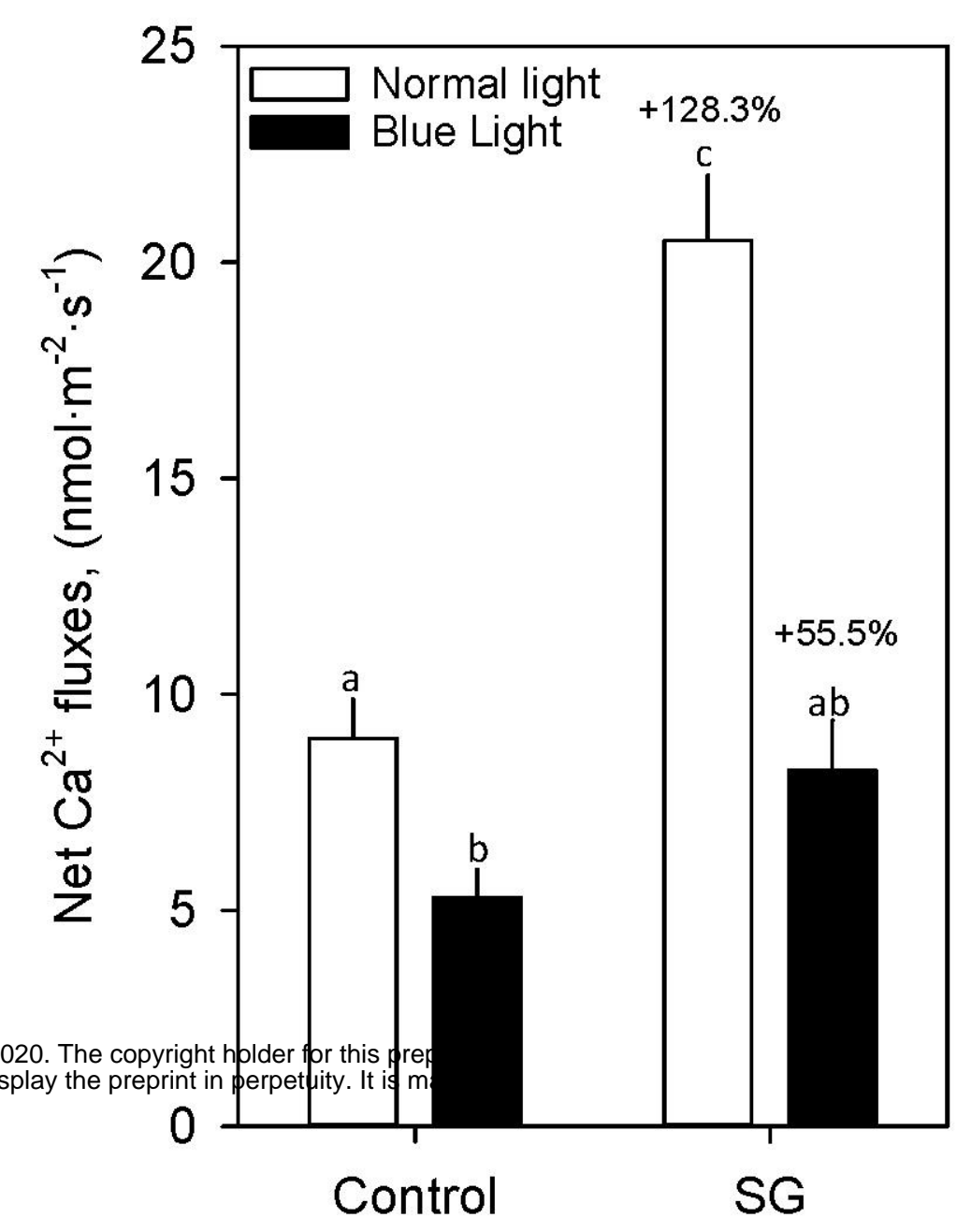

Fig 5 Smart glass (SG) affects ion fluxes and their regulation by blue light in guard cell of capsicum. Net fluxes of $\mathrm{K}^{+}(\mathbf{A}), \mathrm{Ca}^{2+}(\mathbf{B}), \mathrm{H}^{+}(\mathbf{C})$ and $\mathrm{Cl}^{-}(\mathbf{D})$ were recorded from guard cells in leaf epidermal peels. Data are means $\pm \mathrm{SE}$ ( $\mathrm{n}=5$ to 7 plants). Different lowercase letters represent the statistical difference. 


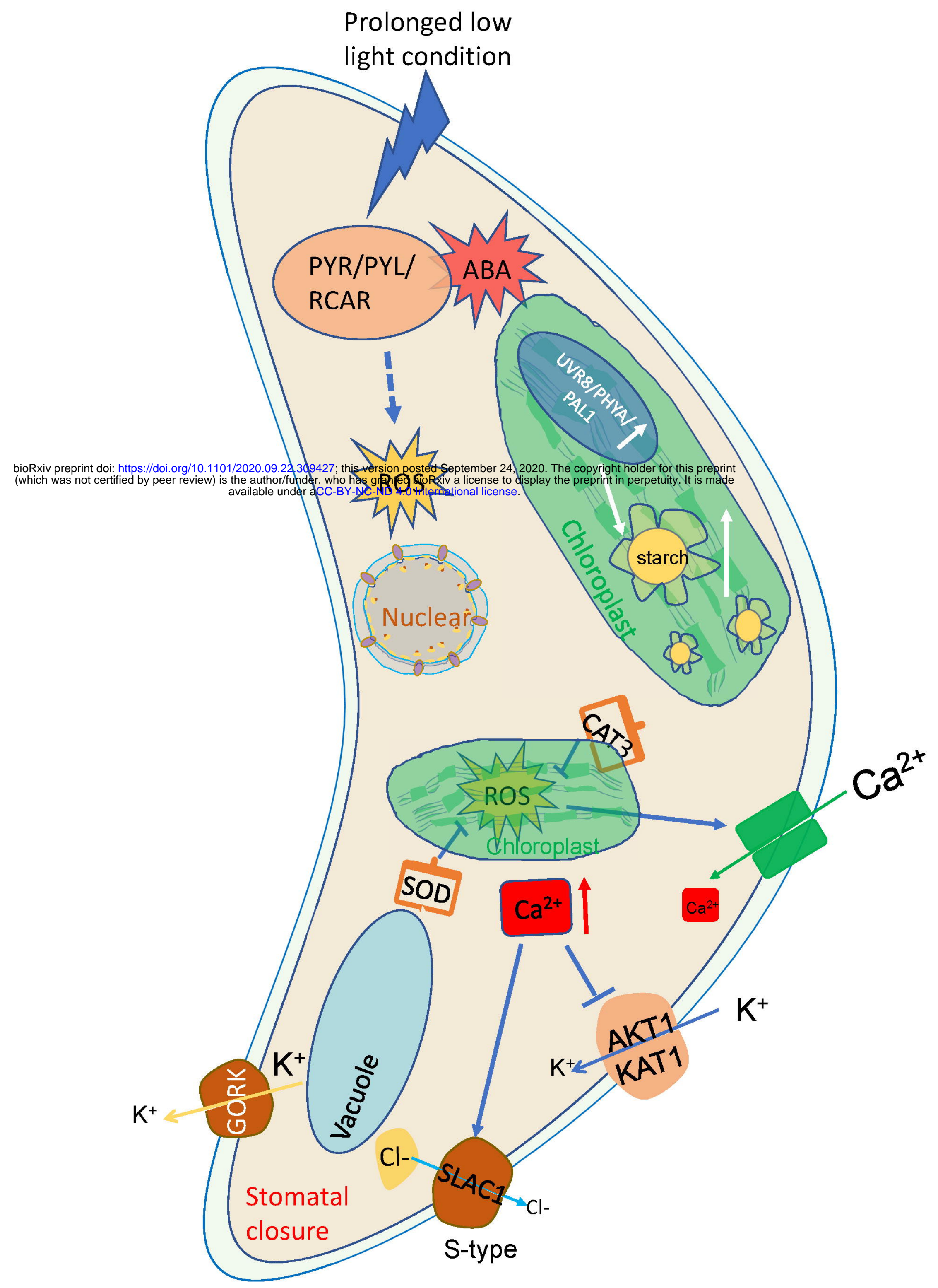


Fig 6 Schematic summary of smart glass (SG)-induced low light condition on guard cell signalling network in capsicum. Under prolonged low light conditions, ABA reception was highly upregulated, leading to the ROS accumulation in guard cells. ROS

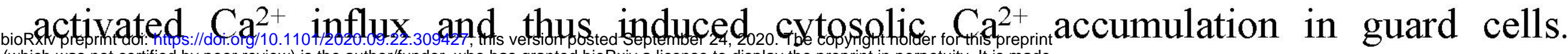

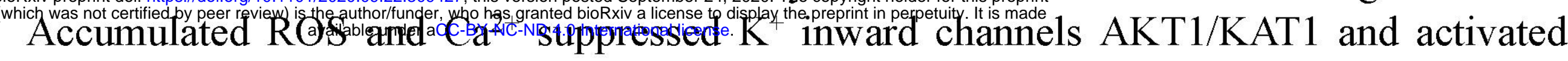
slow anion channels SLAC1(Brandt et al., 2012) and $\mathrm{K}^{+}$outward channel GORK . Besides, photosynthesis related genes also play roles in inducing stomatal closure by accumulating starch in guard cells. 